\title{
Rutin protects against neuronal damage in vitro and ameliorates doxorubicin-induced memory deficits in vivo in Wistar rats
}

This article was published in the following Dove Press journal:

Drug Design, Development and Therapy

29 March 2017

Number of times this article has been viewed

\author{
Grandhi Venkata \\ Ramalingayya \\ Sri Pragnya Cheruku \\ Pawan G Nayak \\ Anoop Kishore \\ Rekha Shenoy \\ Chamallamudi \\ Mallikarjuna Rao \\ Nandakumar Krishnadas \\ Department of Pharmacology, \\ Manipal College of Pharmaceutical \\ Sciences, Manipal University, Manipal, \\ Karnataka, India
}

Correspondence: Nandakumar

Krishnadas

Department of Pharmacology, Manipal

College of Pharmaceutical Sciences,

Manipal University, Madhav Nagar,

Manipal 576104, Karnataka, India

Email mailnandakumar77@gmail.com
Abstract: Doxorubicin (DOX) is the most widely used broad-spectrum anticancer agent, either alone or in combination, for most cancers including breast cancer. Long-term use of chemotherapeutic agents to treat breast cancer patients results in cognitive complications with a negative impact on survivors' quality of life. The study objective was to evaluate rutin (RUT) for its neuroprotective effect against DOX in human neuroblastoma (IMR32) cells in vitro and study its potential to ameliorate DOX-induced cognitive dysfunction in Wistar rats. Cell viability assay (3-[4,5 dimethyl thiazol-2-yl]-2,5-diphenyl tetrazolium bromide), neurite growth assay, detection of apoptosis by (acridine orange/ethidium bromide) staining, intracellular reactive oxygen species (ROS) assay, and flowcytometric analysis were carried out to assess neuroprotective potential against DOX. An in vivo study was conducted for assessing protective effect of RUT against memory deficit associated with DOX-induced chemobrain using object recognition task (ORT). Locomotion was assessed using open field test. Serum biochemistry, acetylcholinesterase, oxidative stress markers in hippocampus, and frontal cortex were assessed. Histopathological analysis of major organ systems was also carried out. Prior exposure to RUT at $100 \mu \mathrm{M}$ protected IMR32 cells from DOX $(1 \mu \mathrm{M})$ neurotoxicity. DOX exposure resulted in increased cellular death, apoptosis, and intracellular ROS generation with inhibition of neurite growth in differentiated IMR32 cells, which was significantly ameliorated by RUT. Cognitive dysfunction was induced in Wistar rats by administering ten cycles of DOX $(2.5 \mathrm{mg} / \mathrm{kg}$, intraperitoneal, once in 5 days), as we observed significant impairment of episodic memory in ORT. Coadministration with RUT ( $50 \mathrm{mg} / \mathrm{kg}$, per os) significantly prevented memory deficits in vivo without any confounding influence on locomotor activity. RUT also offered protection against DOX-induced myelosuppression, cardiotoxicity, and nephrotoxicity. In conclusion, RUT may be a possible adjuvant therapeutic intervention to alleviate cognitive and other complications associated with DOX chemotherapy.

Keywords: breast cancer, chemobrain, cognitive deficit, doxorubicin, episodic memory, object recognition test

\section{Introduction}

Doxorubicin (DOX; adriamycin) is a highly effective broad-spectrum cytotoxic agent used in the treatment of most forms of neoplasia. Using chemotherapeutic agents to particularly manage various neoplastic diseases has opened novel prospects to improve survival rates in many cancers. ${ }^{1}$ The death rates due to breast cancer have gradually decreased in females since 1989. Furthermore, the 10- and 15-year survival rates (for all stages of breast cancer combined) are currently at $83 \%$ and $78 \%$, respectively, in the United States. ${ }^{2}$ Despite this prolonged survival, chemotherapy-induced cognitive 
dysfunction (from now referred to as chemobrain/chemofog or mentalfog) is a debilitating problem that negatively impacts day-to-day activities and quality of life (QOL) in survivors. ${ }^{3,4}$ Chemobrain is a condition characterized by neurocognitive complications, which can often persistently be present for 5-10 years and, in some cases, even lifelong, following the cancer chemotherapy. ${ }^{5-7}$

Cognitive deficits were reported to occur in 34\%-70\% of cancer patients following the chemotherapy. ${ }^{8}$ This phenomenon is particularly evident in breast cancer survivors because of the remarkable improvement in the survival rate, and hence the feasibility of longer follow-up. ${ }^{9-13}$ No treatment has been approved for this particular problem despite the large number of cancer patients reporting memory dysfunction following chemotherapy. ${ }^{14}$ Hence, there exists a great need to develop interventions to combat the cognitive deficits accompanying chemobrain condition so as to improve the health-related QOL in cancer survivors.

Although some agents such as cholinesterase inhibitors, modafinil, and anti-inflammatory agents were tried clinically to treat chemobrain, nonavailability of an effective intervention is still a major lacuna. ${ }^{15,16}$ Complementary and alternative medicine have become promising sources of new drugs of reliable therapeutic potential with a history of long traditional use. ${ }^{17}$ It has been proven that flavonoids can improve cognitive processing through neuroprotection, long-term potentiation, neuronal differentiation, and also by enhancing synaptic plasticity. ${ }^{18-21}$ Flavonoids have an array of beneficial pharmacological activities, viz, memoryenhancing, anticancer, antioxidant, anti-inflammatory, antidepressant, nephroprotective, cardioprotective, neuroprotective effects, etc. ${ }^{20,21}$ Rutin (RUT) is one such important and abundantly available flavonol glycoside having quercetin as its pharmacologically active aglycone moiety and rutinose as glycone, ie, sugar moiety. RUT is a robust antioxidant that possesses anti-inflammatory, antiarthritic, immunomodulatory, antidepressant, antiallergic, and anticancer properties along with potential cardioprotective, neuroprotective, and nephroprotective effects. $^{22-24}$ RUT was found to inhibit proinflammatory cytokines and suppress microglial activation, which would otherwise lead to neuroinflammation. ${ }^{25}$ RUT was effective against trimethyltin-induced spatial memory deficits through amelioration of neuronal damage in hippocampal CA3 subregion, crucial for acquisition learning in rodents. ${ }^{26}$ It also prevented scopolamine-induced cognitive deficits in an inhibitory avoidance test in zebrafish. ${ }^{27}$

Furthermore, RUT showed potential neuroprotective effects against ischemic reperfusion-induced cerebral injury by ameliorating oxidative damage, mitochondrial dysfunction, and neurological impairments; ${ }^{28}$ it also alleviated Alzheimer's disease type neurodegeneration and the associated cognitive impairment induced by intracerebroventricularly injected streptozotocin in rats. ${ }^{29}$

To our knowledge, no earlier report has investigated RUT for its protective potential against DOX chemotherapy and the associated episodic memory deficit. Hence, we hypothesize that RUT may be a potential intervention to alleviate the chemotherapy-induced cognitive dysfunction and may improve the QOL in cancer survivors through its proven pleiotropic beneficial pharmacological actions.

\section{Materials and methods Chemicals and apparatus}

DOX was purchased from Fresenius Kabi Oncology Ltd., Solan, India, while RUT, Trypsin-EDTA, 3-[4,5 dimethyl thiazol-2-yl]-2,5-diphenyl tetrazolium bromide (MTT), fetal bovine serum (FBS), retinoic acid, and acridine orange/ ethidium bromide $(\mathrm{AO} / \mathrm{EB})$ were purchased from HiMedia Laboratories, Mumbai, India. Dichlorofluorescin diacetate and Dulbecco's Modified Eagle's Medium were procured from Sigma-Aldrich Co. LLC, St Louis, MO, USA. Sterile 96- and 6-well tissue culture plates and 25 and $75 \mathrm{~cm}^{2}$ culture flasks, used in this study, were from Tarsons Products Pvt. Ltd., Kolkata, India.

Object recognition task (ORT) was carried out using $49 \mathrm{~cm}$ (length $\times$ width $\times$ height) square boxes. Behavior of animals was monitored with the help of a camera (model: Quickcam Pro9000, Logitech International S.A., Lausanne, Switzerland) that was mounted $150 \mathrm{~cm}$ above the behavioral observation arena. Locomotion and general activity of the animals was assessed using ANYmaze video tracking system (Version 4.82 m, Stoelting Co., Wood Dale, IL, USA).

\section{Animals}

Twelve-week old, healthy $(n=36)$ female Wistar rats, weighing 180-230 g, were used in this study. The protocol was approved by the Institutional Animal Ethics Committee, Kasturba Medical College, Manipal University, Manipal (approval number IAEC/KMC/17/2013) in association with Committee for the Purpose of Control and Supervision on Experimental Animals. Animals were maintained at Central Animal Research Facility of Manipal University, Manipal, as per the directions specified by Committee for the Purpose of Control and Supervision on Experimental Animals guidelines. A 12/12-hour light and dark cycle was maintained, with lights being turned on at $07 \mathrm{am}$. Standard rat pellet diet as well as potable water was provided ad libitum. 


\section{Cell culture and maintenance}

Human neuroblastoma (IMR32) cells were procured from National Centre for Cell Science, Pune, India. Cells were maintained in a $\mathrm{CO}_{2}$ incubator using Dulbecco's Modified Eagle's Medium supplemented with 10\% FBS and suitable antibiotic in sterile cell culture flasks. Use of cell lines for in-vitro studies was approved by Doctoral Advisory Committee, Manipal University, Manipal. All the necessary precautions and care was taken for handling, maintenance and disposal of cell lines as per the protocol designed by the Institution.

\section{In vitro cell viability and dose determination for neuroprotection studies}

Initially we evaluated toxicity profile $\left(\mathrm{IC}_{50}\right)$ of RUT in IMR 32 cells. Cell viability was assessed using MTT assay. ${ }^{30}$

Following 24 hours of seeding, cells were treated with RUT at different concentrations $(50-500 \mu \mathrm{M})$, and cell viability was assessed after 24 hours of exposure. $\mathrm{IC}_{50}$ of DOX was also assessed. Two concentrations that produced $<10 \%$ cell death were selected for assessing neuroprotective activity of test flavonoid RUT against DOX-induced neurotoxic insult.

\section{Neuroprotection studies}

\section{Neuronal viability using MTT assay}

The neuroprotective potential of RUT was tested against DOX-induced neurotoxicity in IMR32 cells using in vitro cell viability assay, ie, MTT. Nontoxic concentrations of test compounds, ie, 50 and $100 \mu \mathrm{M}$ were selected. Following 2-hour inhibition with RUT at both tested concentrations, toxicant DOX $(1 \mu \mathrm{M})$ was added and incubated for a further 24 hours. Then, the intensity of purple color formed was calculated using a microplate reader (ELx800; BioTek Instruments Inc., Winooski, VT, USA) at $540 \mathrm{nM}$, reflecting the direct measurement of cell viability.

\section{Cell cycle analysis by flowcytometry}

One day after seeding, cells were incubated with RUT for 2 hours at $100 \mu \mathrm{M}$, then exposed to DOX at $1 \mu \mathrm{M}$, and further incubated for 24 hours. Then cells were fixed in $70 \% \mathrm{v} / \mathrm{v}$ ethanol for 4 hours and centrifuged, suspended in PBS containing propidium iodide with RNAse, and kept in the dark for 20 minutes. Samples were subjected to analysis in a flow cytometer (BD Accuri ${ }^{\mathrm{TM}}$ C6; BD Biosciences, San Jose, CA, USA). The influence of test compounds, RUT, and DOX on cell population during the cell cycle progression was assessed.
Assessment of morphology and neurite length in differentiated IMR32 cells

After inducing differentiation into neurons with retinoic acid $(10 \mu \mathrm{M})$, the cells were treated with RUT at $100 \mu \mathrm{M}$ for 2 hours, exposed to DOX, and incubated for 24 hours. The cells were then examined using an inverted microscope (Eclipse TS100F; Nikon Instruments Inc., Melville, NY, USA). For measuring neurite length and cell body area, roughly $60-70$ images were captured randomly by scanning each treatment well. The length of each neurite drawn was measured using ImageJ software supplemented with Neuron J plug-in provided by National Institutes of Health (Bethesda, MD, USA). ${ }^{31,32}$ Since neurite width is not equal in all the parts of neuron, the neurite width was calculated by dividing the cell body area with the neurite length.

\section{Detection of apoptosis/necrosis in IMR32 cells by AO/EB staining}

Differentiated neurons were incubated with DOX $(1 \mu \mathrm{M})$, either alone or in combination with RUT (at $100 \mu \mathrm{M}, 2$ hours incubation prior to DOX exposure) in six well plates. Following incubation for 24 hours, wells were washed with PBS and fixed with $1 \mathrm{~mL}$ of ice-cold ethanol (100\%) for 10 minutes at room temperature. Then, after washing with $\mathrm{PBS}, 1 \mathrm{~mL}$ AO/EB reagent stain was added to each well and incubated at $37^{\circ} \mathrm{C}$ for 10 minutes. Individual cells were observed under an inverted microscope with the use of fluorescence filters. Morphology of apoptotic and necrotic cells was recognized based on the staining pattern as described previously. ${ }^{33}$

\section{Quantitative estimation of apoptosis by Annexin $V$ assay}

The Annexin V apoptosis assay was performed as per the manufacturer's instruction manual. Briefly, $2 \times 10^{4}$ differentiated cells/well, seeded in a six-well tissue culture plate, were treated with $1 \mu \mathrm{M}$ DOX alone or a combination of DOX $(1 \mu \mathrm{M})$ and RUT $(50$ and $100 \mu \mathrm{M})$ after 12 hours of seeding and then incubated for 48 hours. After 48 hours, the cells were trypsinized and centrifuged. After centrifugation, the cell pellets were resuspended in $100 \mu \mathrm{L}$ of media containing $10 \%$ FBS. Approximately $100 \mu \mathrm{L}$ Annexin V was added to the cell suspension and incubated for 20 minutes. The apoptotic profile of the cells was analyzed using Muse ${ }^{\circledR}$ Cell Analyzer (Model Number 0500-3115, Merck Millipore, Billerica, MA, USA).

\section{Intracellular reactive oxygen species estimation}

IMR32 cells in black 96-well plates were incubated with RUT at 50 and $100 \mu \mathrm{M}$ for 2 hours and then subjected to DOX $(1 \mu \mathrm{M})$ exposure. After 24-hour inhibition, culture supernatants were discarded and replaced with $100 \mu \mathrm{L}$ of 
dichlorofluorescein diacetate $(100 \mu \mathrm{M})$. Following 1-hour incubation with fluorescence dye, cells were washed with sterile Hank's balanced salt solution. Fluorescence intensity was measured with the help of a fluorescence microplate reader (FLx800; BioTek Instruments Inc., Winooski, VT, USA). The reactive oxygen species (ROS) level was measured and calculated with respect to media control. ${ }^{34}$

\section{In vivo chemobrain study}

\section{Experimental design}

Four experimental groups ( $n=9$ of each) were used in this study. Groups 1 and 4 were given normal saline, intraperitoneal, while groups 2 and group 3 were treated with DOX ( $2.5 \mathrm{mg} / \mathrm{kg}$, intraperitoneal) once in 5 days over a period of 50 days. Animals of groups 2 and 3 were administered daily doses of sodium carboxymethyl cellulose $(0.25 \% \mathrm{w} / \mathrm{v}$ in water for injection, intraperitoneal [ip]) and RUT (50 mg/kg, per os [po]), formulated as suspension in carboxymethyl cellulose, respectively. Dosing was begun from 1 week before first DOX cycle and continued thereafter until the end of study. Group 4 was administered RUT at $50 \mathrm{mg} / \mathrm{kg}$, po, but without DOX, to identify the chronic per se effect of this flavonoid on cognitive function. The treatment protocol lasted over a period of 65 days as shown in Figure 1. The doses selected were based on the previous studies and also the earlier work conducted in our laboratory. ${ }^{35,55}$

\section{ORT for episodic memory}

Episodic memory was assessed in rodents using ORT. The test also involves the working memory component to some extent. Procedures adopted were based on earlier reports, with a few modifications. ${ }^{36,37}$ Briefly, the experiment was conducted over a period of 2 days between 09 am and 05 pm and comprised three phases, viz, habituation, familiarization, and choice trials. On the first day, animals were habituated to the square arenas for a period of 20 minutes. In pilot studies on female Wistar rats, we noticed that control animals were able to remember a familiar object up to an intertrial interval (ITI) of 2 hours. ${ }^{35}$ Therefore, on day 2, animals were subjected to object recognition test with this ITI of 2 hours. In the familiarization trial, animals were allowed to explore a pair of similar objects. The movement of rats toward the objects was recorded by an expert observer (blind to treatments) using a camera (LogitechPro9000, Logitech International S.A., Lausanne, Switzerland). Recognition trial was performed by replacing one of the familiar objects with a novel object, and the cumulative exploration time of each animal toward a familiar or novel object was noted for 3-minute trial duration. Recognition index and discriminative index that reflect the animal's memory for objects were determined. ${ }^{38}$

\section{Body weight monitoring}

Body weights were recorded every 3 days throughout the study period. Average body weights were compared among the various experimental groups.

\section{TNF- $\alpha$ levels}

The level of TNF- $\alpha$ was estimated using ELISA kit (Novex ${ }^{\mathrm{TM}}$ Kit Number KRC3011, Thermo Fisher Scientific Inc., Waltham, MA, USA) in hippocampal and frontal cortex regions, as per the manufacturer's instructions.

\section{Open-field test for assessing locomotor activity}

Rats were assessed for locomotion using an open-field (OF) test. ${ }^{39,40}$ Briefly, rats were individually placed in OF boxes for 15 minutes. Using ANYmaze video-tracking system, general activity, distance $(\mathrm{cm})$ traveled, and mean velocity $(\mathrm{cm} / \mathrm{s})$ of animals during test duration were evaluated.

\section{Hematological analysis}

Complete blood profile was determined using automated veterinary blood cell counter (Model: PCE210 VET, ERMA Inc., Tokyo, Japan).

\section{Preventive treatment daily with flavonoid, RUT throughout study period starting from day 1}

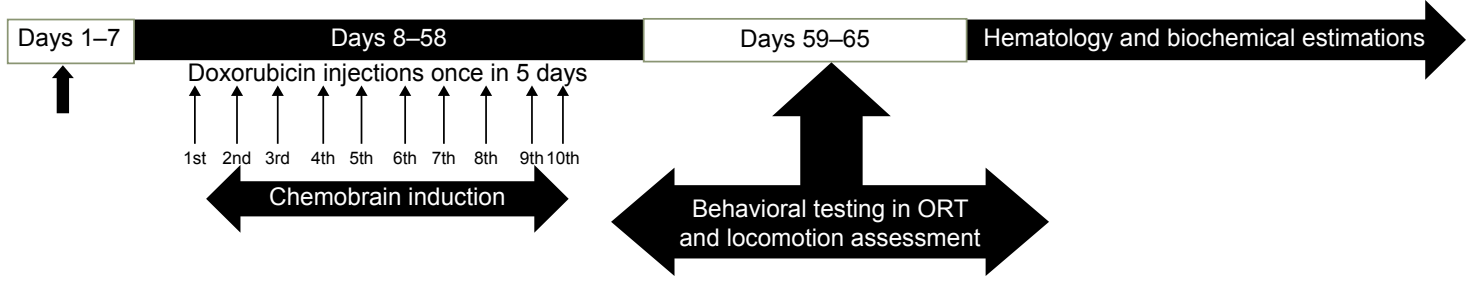

Figure I Chemobrain protocol adopted.

Note: Protocol for inducing chemobrain upon DOX administration to assess RUT for possible protective effect against DOX-induced chemobrain in Wistar rats. Abbreviations: RUT, rutin; DOX, doxorubicin; ORT, object recognition test. 


\section{Organ index}

Following blood sampling, animals were deeply anesthetized with ketamine, and whole-body perfusion was carried out with ice-cold saline. Kidney, liver, brain, and heart were collected. The weight of each organ per $100 \mathrm{~g}$ body weight of the animal was calculated as organ index and comparison was made among the different treatment groups.

\section{Oxidative stress markers}

The antioxidant defense systems, viz, superoxide dismutase (SOD), catalase, glutathione (GSH), and total thiols levels were estimated in hippocampus and frontal cortex regions of brain. ${ }^{41-45}$

\section{Acetylcholinesterase activity}

Following hippocampal and frontal cortex isolation, samples were homogenized with phosphate buffer ( $\mathrm{pH} 7.4)$, and supernatants were collected for estimation of acetyl cholinesterase. $^{46}$

\section{Serum cortisol estimation}

Cortisol levels in serum were assessed using rat cortisol ELISA kit (Elabscience Biotechnology Co. Ltd., Wuhan, People's Republic of China), following the manufacturer's procedure.

\section{Serum biochemistry}

Serum analysis was carried out for cholesterol, total protein, urea, creatinine, creatine kinase, aspartate transaminase, alanine transaminase, alkaline phosphatase, etc using fully automated autoanalyzer (Cobas C111; Roche Diagnostics India Pvt. Ltd., Basel, Switzerland), following manufacturer's standard protocol.

\section{Histopathology}

Histopathological analysis was conducted for all major organs, viz, liver, heart, kidney, and cerebral cortex following the conventional tissue processing in gradient alcohol and xylene with the use of eosin/hematoxylin staining. Gross histopathological changes as a result of toxicant, ie, DOX and also the treatment, RUT was reported.

\section{Statistical analysis}

Statistical analysis was carried out using Prism Version 6.05 (fully functional demo; GraphPad Software Inc., La Jolla, CA, USA). All data are expressed as mean \pm standard error of the mean of specified number of samples. Cell viability, $\%$ apoptotic cells, and intracellular ROS measures were analyzed by Kruskal-Wallis test, followed by Dunn's post hoc test. For behavioral analysis, exploration time was compared by Student's paired $t$-test (within the group and between the objects), whereas recognition index and discriminative index were analyzed by using Kruskal-Wallis test, followed by Dunn's post hoc test. Locomotor activity, organ index, body weight, neurite length, acetyl cholinesterase, and hematological analyses were carried out by one-way analysis of variance, followed by Dunnett's post hoc test. A value of $P<0.05$ was considered as statistically significant.

\section{Results \\ Cell viability and dose fixation for neuroprotection studies}

During the preliminary cytotoxicity assessment of flavonoids or the toxicant in IMR32 cells, the $\mathrm{IC}_{50}$ for RUT, and its aglycone, quercetin was found to be 350 and $250 \mu \mathrm{M}$, respectively. Dose-dependent cytotoxic effect was observed for DOX in the concentration range $(0.01-5 \mu \mathrm{M})$ tested and $\mathrm{IC}_{50}$ of DOX was found to be $1 \mu \mathrm{M}$. Approximately $80 \%-90 \%$ cell viability was observed for RUT and quercetin at 50 and $100 \mu \mathrm{M}$; therefore, the same concentrations have been used to test the neuroprotective ability of flavonoids in further studies evaluating protective effect against DOX.

\section{Evaluation of neuroprotective effect of flavonoids in vitro against DOX}

Neuronal cell viability by MTT assay

DOX $(1 \mu \mathrm{M})$ produced $49.63 \%$ viability in IMR32 cells. However, prior incubation with flavonoids for 2 hours (RUT produced $64.89 \%$ and $73.93 \%$ viability at 50 and $100 \mu \mathrm{M}$, respectively) significantly $(P<0.001)$ prevented DOXinduced cell death in a dose-dependent manner, the most effective being $100 \mu \mathrm{M}$. Since $100 \mu \mathrm{M}$ concentration showed comparatively more protection against DOX, we used this concentration, ie, $100 \mu \mathrm{M}$ in later studies (Table 1).

Table I Percentage viability in MTT assay

\begin{tabular}{lll}
\hline Serial number & Treatment & \% viability \\
\hline $\mathrm{I}$ & DMSO media control & $100.0 \pm 1.914^{*}$ \\
2 & DOX control, I $\mu \mathrm{M}$ & $49.63 \pm 1.44$ \\
3 & DOX, I $\mu \mathrm{M}$ + RUT 50 $\mu \mathrm{M}$ & $64.89 \pm 0.948^{*}$ \\
4 & DOX, I $\mu \mathrm{M}$ + RUT I00 $\mu \mathrm{M}$ & $73.93 \pm 0.84 \mathrm{I}^{*}$ \\
\hline
\end{tabular}

Notes: Data represent mean \pm SEM of three tests in triplicates for protective effect of RUT on cell viability against DOX-induced neurotoxicity in MTT assay on IMR32 cells, ${ }^{* P}<0.001$ compared to DOX control.

Abbreviations: DMSO, dimethyl sulfoxide; DOX, doxorubicin; MTT, 3-[4,5 dimethyl thiazol-2-yl]-2,5-diphenyl tetrazolium bromide; RUT, rutin; SEM, standard error of the mean. 

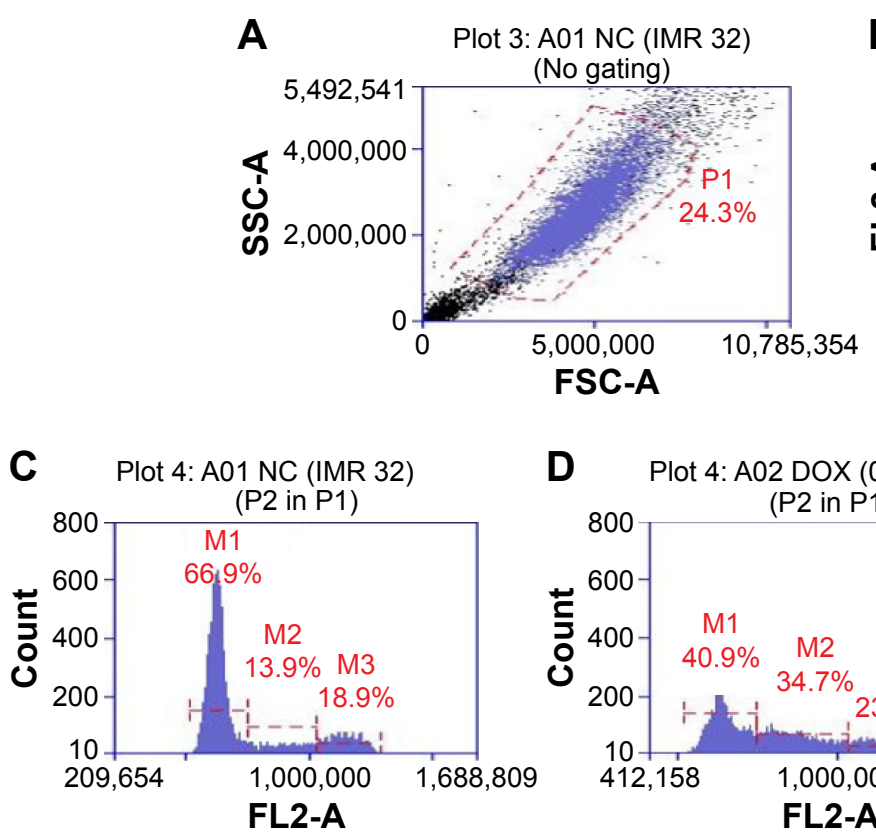

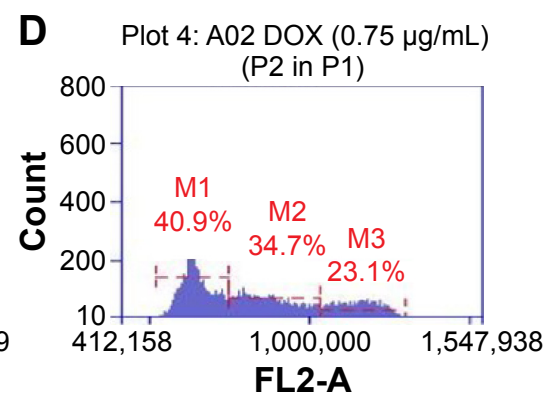

Figure 2 Flow cytometric analysis in IMR32 cells.

Notes: Histograms represent the effect of RUT on DOX-induced changes in percentage of cell populations in various phases of cell cycle in IMR32 cells. (A), whole cell population with cell debris; (B) gated for actual cell population after removing cell debris and doublet cells; (C) normal control; (D) DOX only treated; (E) RUT treatment prior to DOX. MI, M2, and $M 3$ indicate $G_{0} / G_{1}$ phase, $S$ phase, and $G_{2} / M$ phase respectively.

Abbreviations: DOX, doxorubicin; RUT, rutin; NC, normal control; PI, total cell population; P2, single cell population; FL2-A, propidium iodide fluorescence pulse (area); SSC-A, side scatter (area); FSC-A, forward scatter (area).

\section{Cell cycle analysis by flow cytometry}

Treatment with DOX $(1 \mu \mathrm{M})$ arrested the cell cycle progression in IMR 32 cells at $\mathrm{G}_{2} / \mathrm{M}$ and $\mathrm{S}$ phases. Pretreatment with RUT partially prevented DOX-induced changes (Figure 2) with the cells predominately in $G_{0} / G_{1}$ and $S$ phases.

\section{Morphological changes and assessment of neurite length in differentiated IMR32 cells}

Treatment with DOX induced morphological alterations in neuronal cells. The nucleus was condensed, and cell membrane was fragmented due to toxicant insult (Figure 3C). However, prior treatment with RUT resulted in the cells retaining their normal morphology (Figure 3D). DOX exposure significantly $(P<0.001)$ inhibited the development of neurite outgrowth in differentiated IMR32 cells compared to media control. However, treatment with RUT at $100 \mu \mathrm{M}$ produced prominent establishment of neurite and, hence, significantly $(P<0.001)$ averted inhibitory effect of DOX on neurite growth in IMR32 cells. This indicates that RUT protected the differentiated neuronal cells in course of neurite
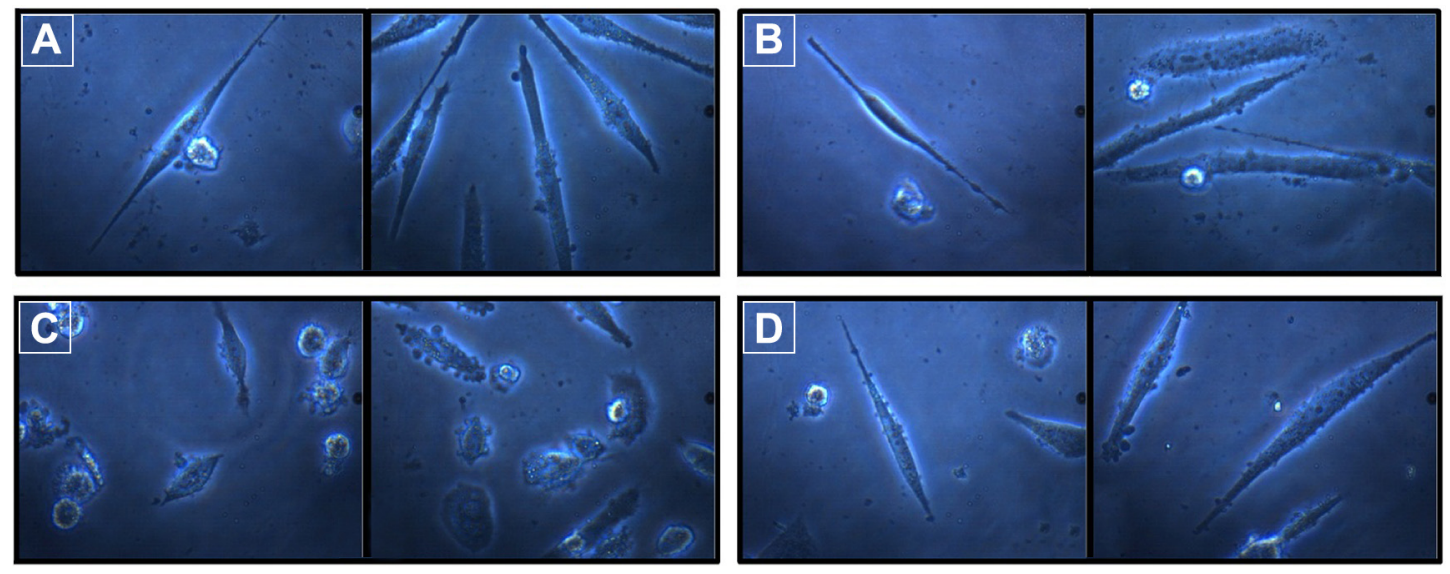

Figure 3 Morphology of neurite establishment and growth in differentiated IMR32 cells.

Notes: Effect of DOX and the flavonoid, RUT on neurite length, and morphology of differentiated IMR32 cells; (A) normal control; (B) rutin-treated cells; (C) DOX control; (D) rutin treatment prior to DOX challenge.

Abbreviations: DOX, doxorubicin; RUT, rutin. 
A

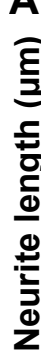

ह
2,000

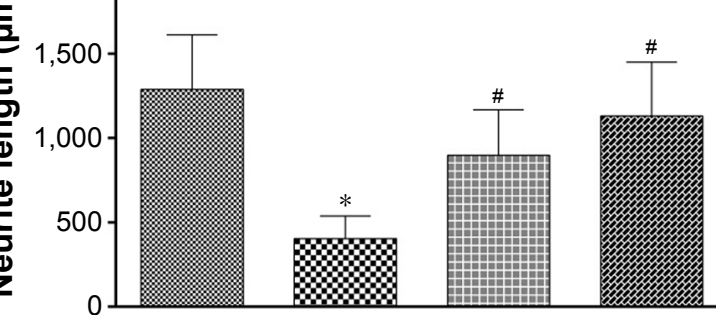

B

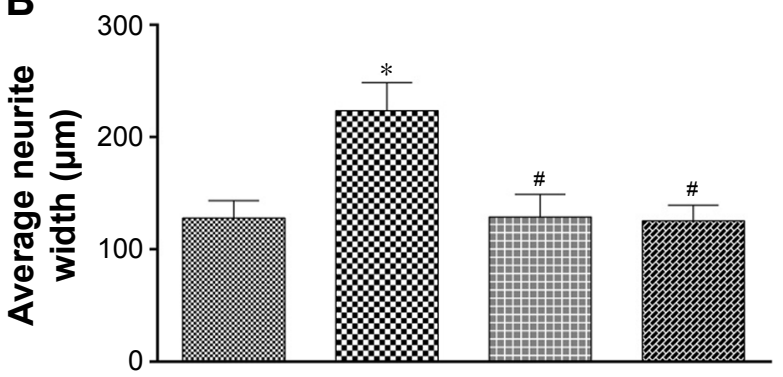

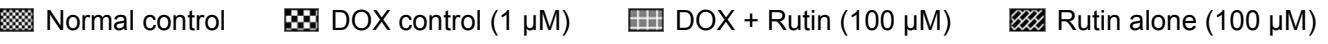

Figure 4 Effect of DOX and RUT on (A) neurite length and (B) neurite width in IMR32 cells.

Notes: Illustration represents mean \pm SEM of neurite length in micrometers for the protective effect of RUT against DOX-induced neurite inhibition in IMR32 cells, $* P<0.001$ vs normal control, ${ }^{\#}<<0.001$ vs DOX control.

Abbreviations: DOX, doxorubicin; RUT, rutin; SEM, standard error of the mean.

development against the neurotoxic insult produced by DOX. In contrast to neurite length, DOX treatment significantly increased the neurite width when compared to normal control. This increase in neurite width was attenuated by pretreatment with RUT. The neurite establishment, length, and width are illustrated in Figures 3 and 4.

\section{Detection of apoptosis/necrosis by $\mathrm{AO} / \mathrm{EB}$ staining} $\mathrm{AO} / \mathrm{EB}$ staining showed that DOX produced marked apoptotic cell death in IMR32 cells with the finding of bright condensed nuclei and fragmented cellular structures (Figure 5). The percentage of cells with early apoptotic and late apoptotic morphology were noted. The percentage of apoptotic cells was significantly $(P<0.001)$ high in DOX group when compared to the normal control (Table 2). RUT prior treatment reversed the DOX-induced elevation of apoptotic cell death and produced significant decline $(P<0.01)$ in percentage of apoptotic cells. This shows that neuroprotective potential of flavonoids is through inhibition of apoptotic pathways.

\section{Apoptotic detection by Annexin $\mathrm{V}$ staining}

Treatment with DOX $(1 \mu \mathrm{M})$ induced early and late apoptosis in IMR32 cells (Figure 6B). Pretreatment with RUT (50 and $100 \mu \mathrm{M}$ ) significantly decreased the number of apoptotic cells induced by DOX (Figure 6E), indicating the
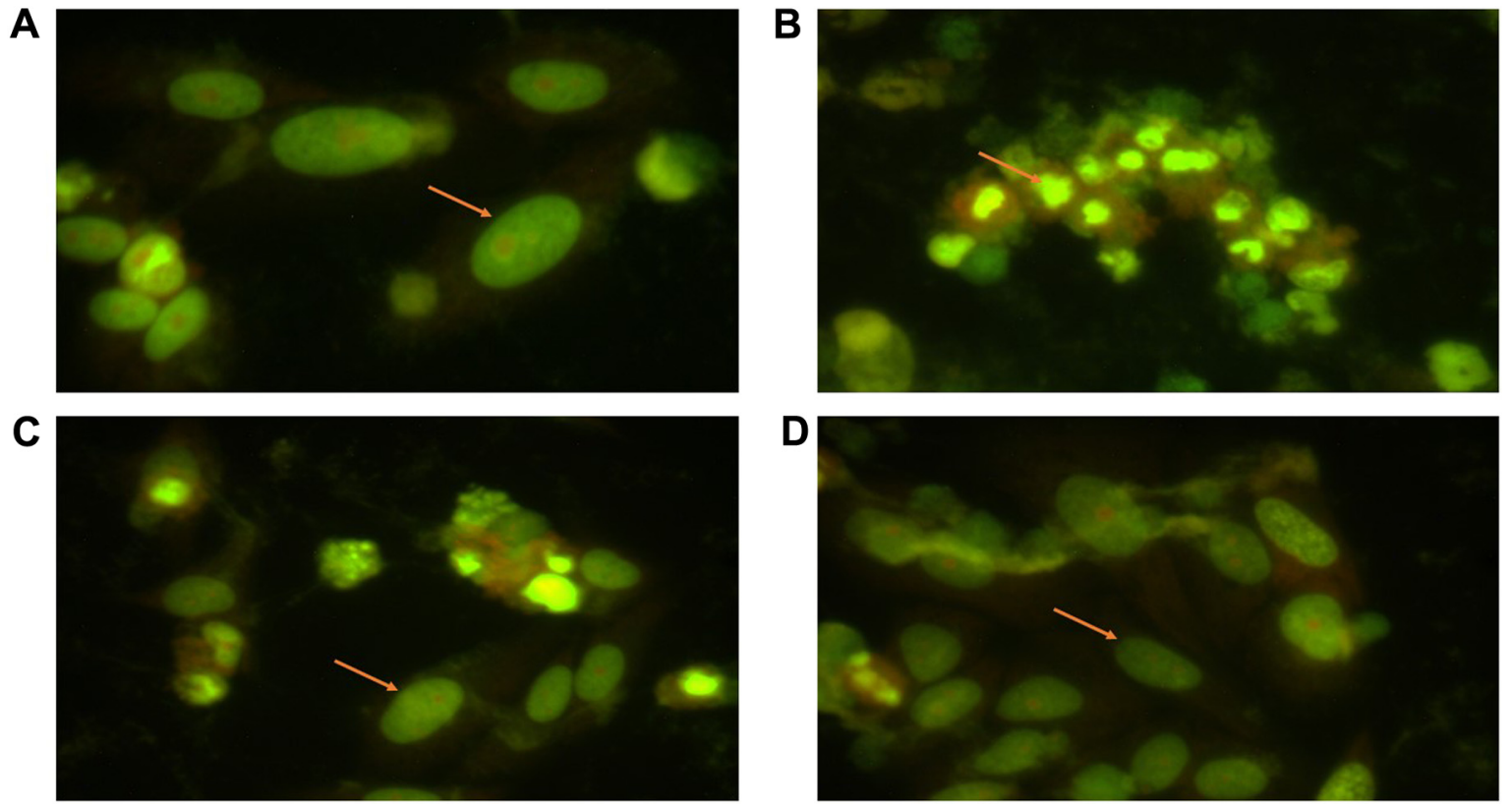

Figure 5 Effect of treatments on apoptotic cell death in IMR32 cells.

Notes: Illustration represents the effect of RUT on DOX-induced apoptosis in AO/EB staining apoptosis assay; (A) normal control; (B) DOX control; (C) cells treated with RUT prior to DOX; (D) cells treated with rutin only. Arrows illustrate the represent images of IMR32 cells with normal (A, C and D) or apoptotic (B) morphology. Abbreviations: DOX, doxorubicin; AO/EB, acridine orange/ethidium bromide; RUT, rutin. 
Table 2 Percentage of apoptotic cells in AO/EB staining

\begin{tabular}{lll}
\hline Serial number & Treatment & \% apoptotic cells \\
\hline I & Normal control & $16.54 \pm 1.06$ \\
2 & DOX control, I $\mu M$ & $54.78 \pm 3.56^{*}$ \\
3 & DOX, I $\mu M+$ RUT, I00 $\mu M$ & $31.22 \pm 3.76^{\#}$ \\
4 & RUT, I00 $\mu \mathrm{M}$ & $12.56 \pm 2.76^{\#}$ \\
\hline
\end{tabular}

Notes: Data represent mean \pm SEM of three tests in triplicate for the effect of RUT on cellular apoptosis against DOX-induced neurotoxicity in differentiated IMR32 cells, ${ }^{*} P<0.001$ compared to normal control; ${ }^{*} P<0.01$ and ${ }^{\# P} P<0.001$ compared to DOX control.

Abbreviations: DOX, doxorubicin; RUT, rutin; AO/EB, acridine orange/ethidium bromide; SEM, standard error of the mean.

neuroprotective effect of RUT. Furthermore, RUT prevented early, rather than late, apoptosis in IMR32 cell lines challenged with DOX (Figure 6C and D).

\section{Intracellular ROS estimation}

DOX produced significant $(P<0.001)$ elevation of intracellular ROS as compared to the normal media control. Prior treatment with RUT significantly $(P<0.001)$ inhibited the ROS generation by DOX. This shows the potential antioxidant role of this flavonoid and its ability to scavenge the intracellular ROS that was generated by DOX (Figure 7).

\section{In vivo chemobrain study for evaluating RUT as possible intervention ORT for episodic memory}

Following an ITI of 2 hours, vehicle- and saline-treated animals were able to remember the familiar object, as they discriminated the novel object from familiar one in choice trial. Animals treated with vehicle and DOX $(2.5 \mathrm{mg} / \mathrm{kg}$, intraperitoneal) spent almost equal time exploring both familiar and novel objects, indicating their inability to discriminate between the objects due to lack of episodic recognition memory for familiar object. However, chronic treatment with RUT (50 mg/kg, po) prevented DOX-induced episodic like memory deficit in ORT, and the rats spent significantly more time exploring the novel object when compared to the familiar object. Rats treated with RUT and DOX were able to discriminate the novel object from the familiar one, which was also indicated by significant increase in recognition and discriminative indices as compared to DOX control (Figure 8).

\section{Body weight measurements}

We found that there was a gradual increase in body weight in all the groups. However, the DOX control group had comparatively lower average body weight than the other groups. This was not statistically significant. Highest mean body weight was observed in group treated with only vehicle or RUT. Treatment with RUT at the dose of $50 \mathrm{mg} / \mathrm{kg}$, po, along with DOX for 60 days has resulted in a reversal of loss of body weight due to DOX treatment (Figure 9).

\section{TNF- $\alpha$ levels}

The level of TNF- $\alpha$ was significantly elevated in hippocampal and frontal cortex regions in the DOX control group as compared to the vehicle control. Chronic treatment with RUT prevented the DOX-induced rise in TNF- $\alpha$ levels significantly in hippocampus and frontal cortex (Figure 10).

\section{OF test for locomotor activity}

It was found that neither DOX nor RUT had any influence on locomotor activity. Hence, there was no confounding influence of DOX or RUT in the assessment of episodic memory using ORT. No significant differences for either distance traveled or mean velocity were noted among the four treatment groups, which proves the validity of the ORT in assessing the episodic memory deficits associated with DOX chemotherapy (Figure 11).

\section{Hematological analysis}

Treatment with DOX over 50 days resulted in a significant $(P<0.01)$ reduction in red blood cells $(\mathrm{RBC})$ and hemoglobin compared to vehicle control animals. This myelosuppressive effect of DOX was significantly $(P<0.01)$ reversed by RUT coadministration at the dose of $50 \mathrm{mg} / \mathrm{kg}$, po. White blood cells (WBC) counts were comparatively reduced in DOX control group with respect to vehicle. However, the differences were not statistically significant. Rats treated with only RUT without any DOX treatment showed improvement of RBC and hemoglobin when compared to the normal vehicle control, which supports RUT's protective effect on DOX-induced hematological changes (Table 3).

\section{Organ index}

No significant difference was observed among the treatment groups for organ index of any of the organs studied, ie, heart, liver, brain, kidney, etc (data not shown).

\section{Oxidative stress status}

Catalase, GSH, total thiols, and SOD levels were significantly $(P<0.01)$ lower in frontal cortex and hippocampal regions for the DOX control group as compared to the normal control. However, these alterations were significantly $(P<0.01)$ prevented by coadministration of RUT at a dose 
A

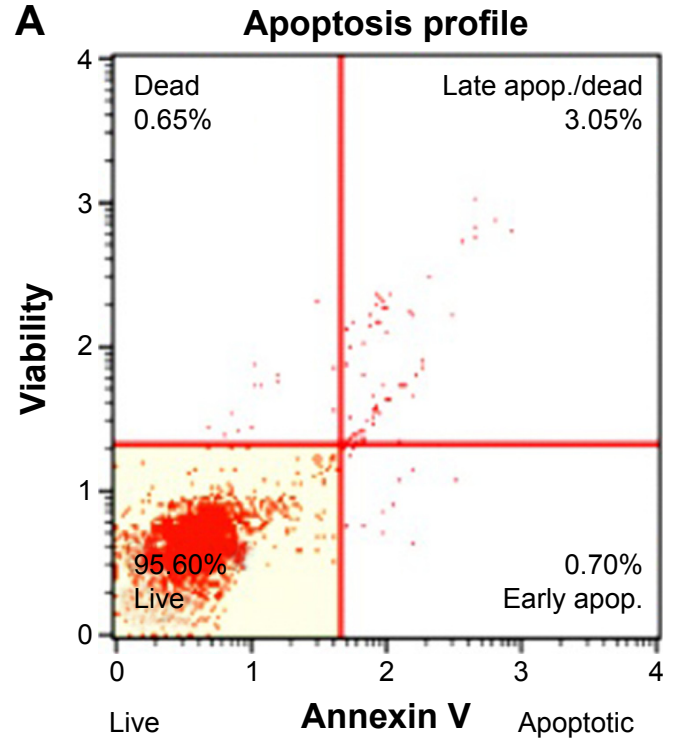

C

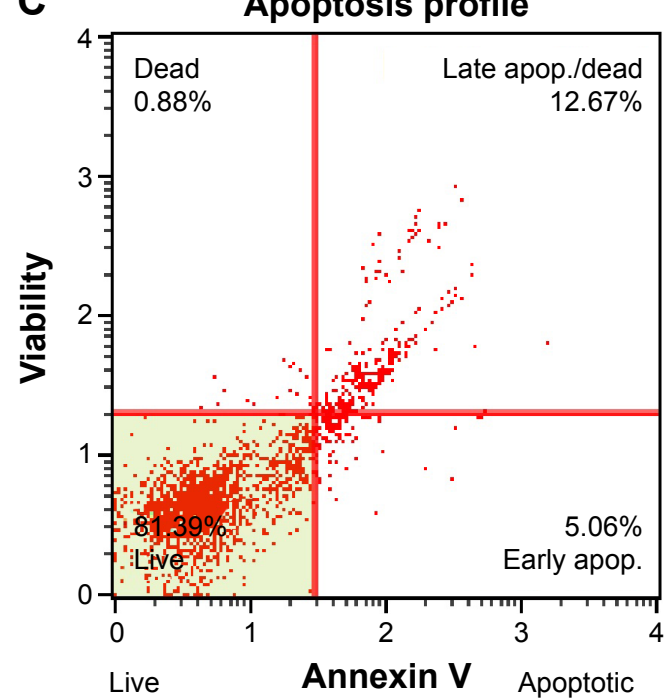

B

Apoptosis profile

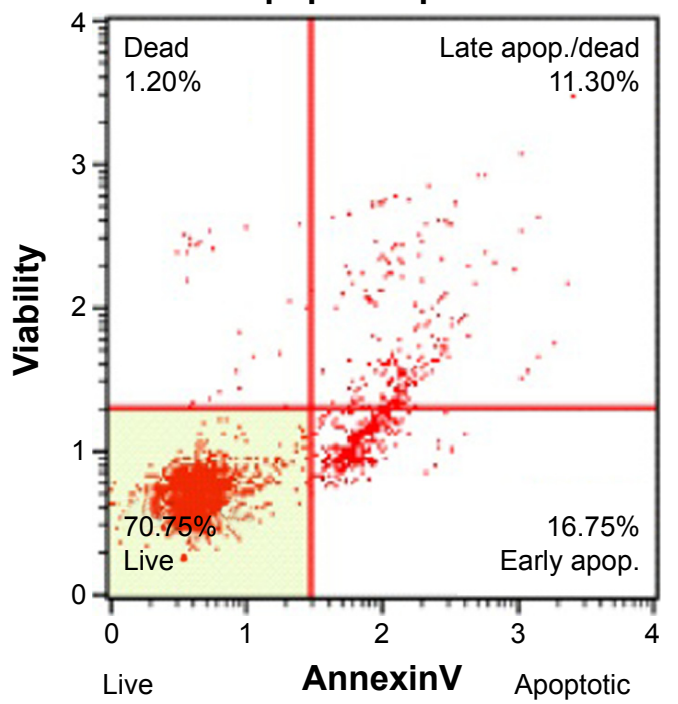

D

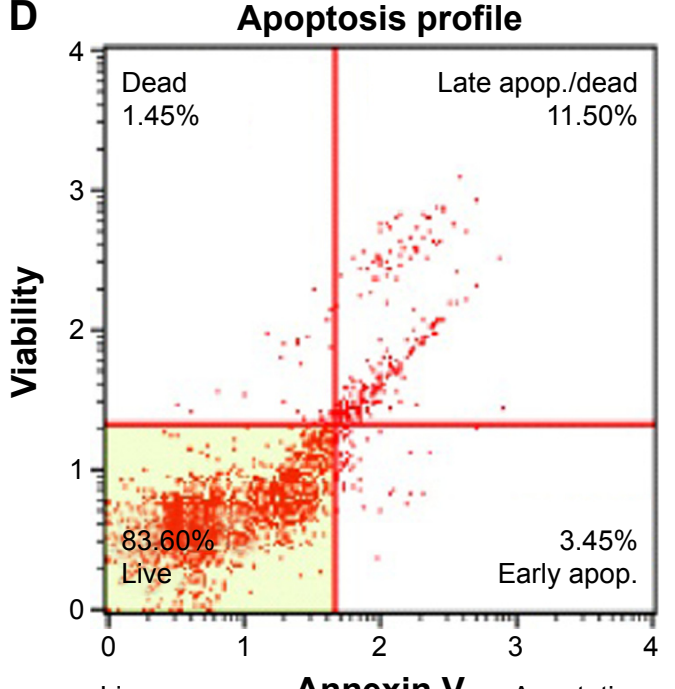

Live

E

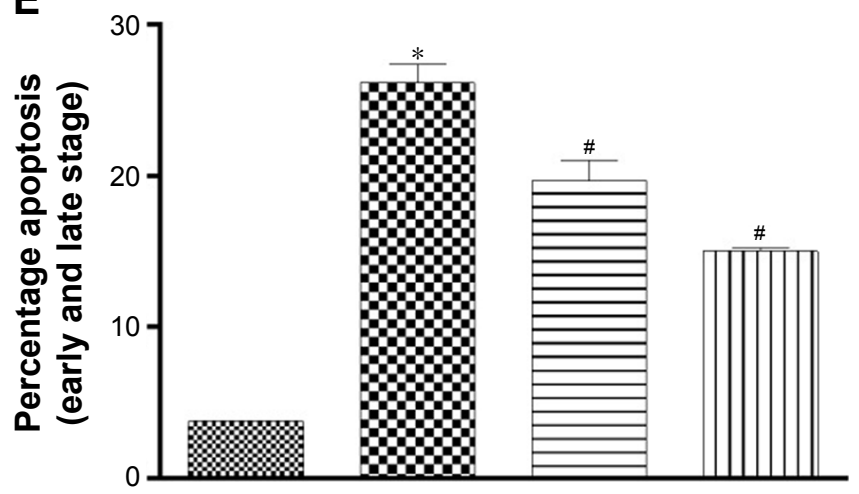

Treatments

Figure 6 Quantitative analysis of the effect of treatments on apoptotic patterns in IMR32 cells.

Notes: Illustration represents the effect of RUT on DOX-induced apoptosis in Annexin V staining; (A) normal cells; (B) DOX treated; (C) cells treated with RUT (50 $\mu \mathrm{M})$ prior to DOX; (D) cells treated with RUT (I00 $\mu \mathrm{M})$ prior to DOX; (E) percentage apoptosis in cells due to treatments where values are represented as mean \pm SEM. $* P<0.00$ I compared to normal control; $\# P<0.01$ compared to DOX control.

Abbreviations: apop, apoptosis; DOX, doxorubicin; RUT, rutin; SEM, standard error of the mean. 


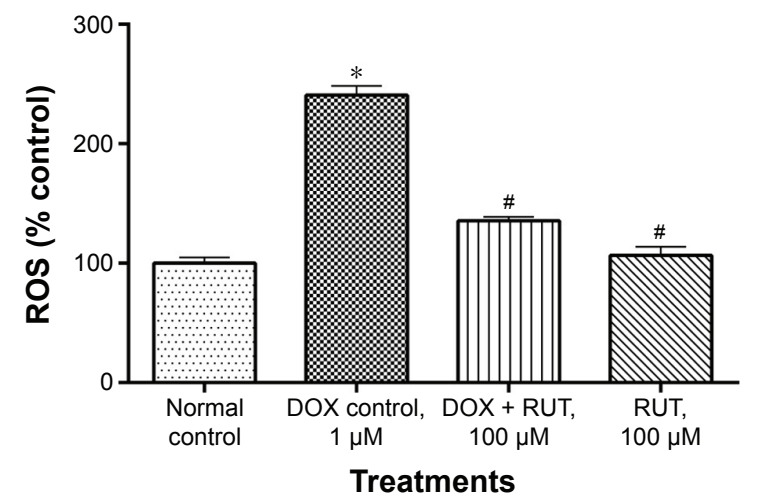

Figure 7 Effect of treatments on intracellular ROS generation.

Notes: Illustration represents the effect of RUT on DOX-induced intracellular ROS generation in IMR32 cells, ${ }^{* P}<0.00$ I compared to normal control, ${ }^{*} P<0.00$ I compared to DOX control.

Abbreviations: DOX, doxorubicin; ROS, reactive oxygen species; RUT, rutin.

of $50 \mathrm{mg} / \mathrm{kg}$, po. Treatment with RUT alone did not affect any of the aforementioned antioxidant defense systems (Table 4).

\section{Hippocampal and frontal cortex acetylcholinesterase} activity

No significant difference in acetylcholinesterase activity was noted among the treatment groups, either in frontal cortex or hippocampus. DOX treatment did not produce any inhibition or activation of this enzyme activity. This shows that the pathophysiology of chemobrain is different from Alzheimer's disease-associated dementia (Table 5).

\section{Serum cortisol levels}

Changes in serum cortisol levels were found to be insignificant among the treated groups, showing that the test treatments did not influence cognitive assessment with depression-like states (Data not shown).

\section{Serum biochemistry}

It was noted that the creatine kinase, urea, triglyceride, and total cholesterol levels were significantly elevated in DOX control group compared to vehicle control. However, RUT coadministration prevented the changes observed with DOX treatment. Other parameters, viz, glucose, AST, ALT, ALP, total bilirubin, creatinine, total protein, and albumin were found to be unaltered among different groups (Table 6).

\section{Histopathology}

Histopathological analysis revealed that heart, liver, kidney, and cerebral cortex samples of the animals treated with DOX showed abnormal architecture with degenerative changes as
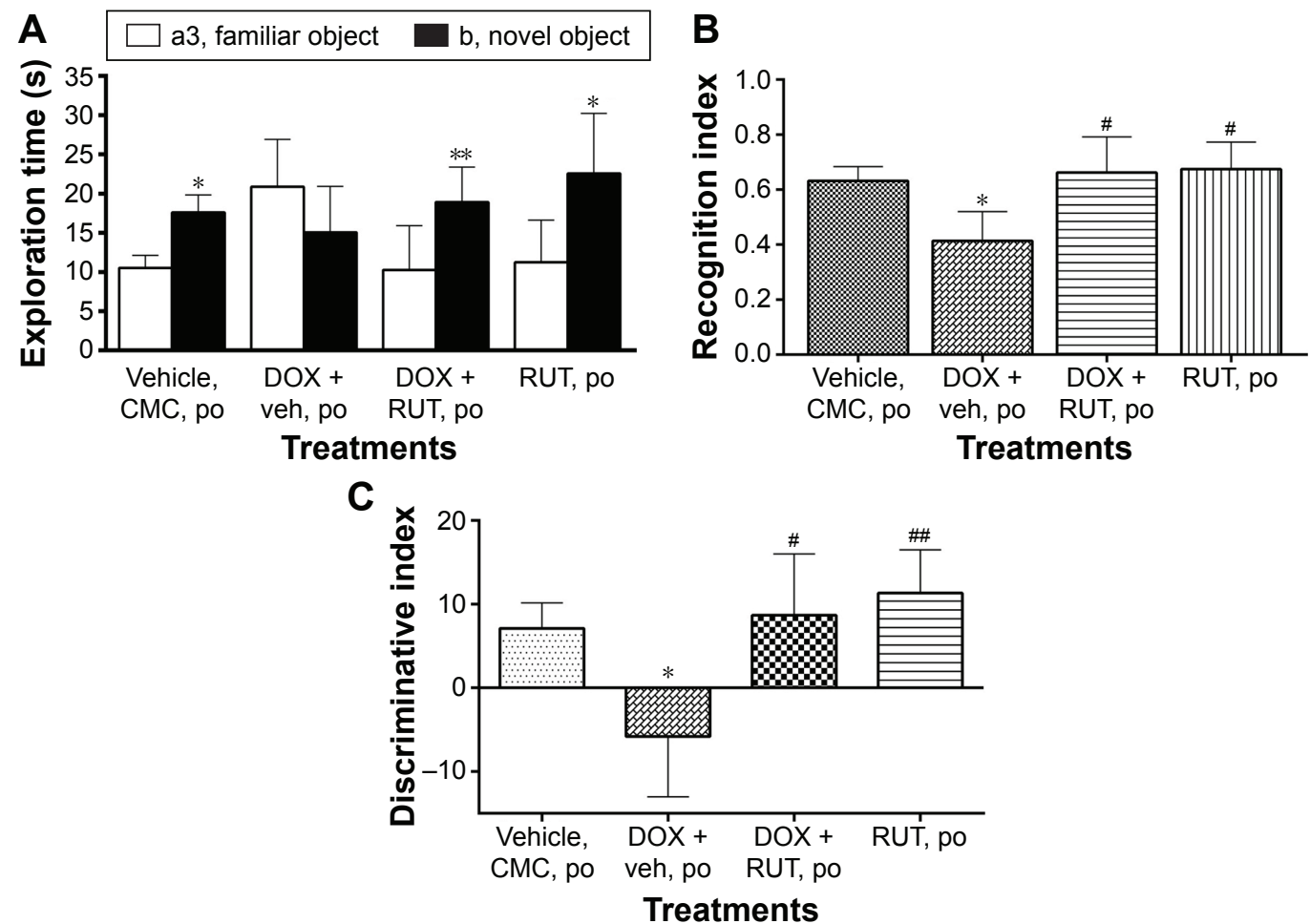

Figure 8 Effect of RUT against DOX-induced episodic memory deficits in Wistar rats.

Notes: Illustration represents mean \pm SEM of $(\mathbf{A})$ exploration time of novel or familiar objects $(* P<0.00$ I, $* * P<0.01$ vs familiar object), $(\mathbf{B})$ recognition, and $(\mathbf{C})$ discriminative indices ( ${ }^{*} P<0.05$ vs vehicle control, ${ }^{\#} P<0.01,{ }^{\#} P<0.00$ I vs $D O X$ control) of different groups of rats in choice trial in ORT ( $=8-9$ ).

Abbreviations: CMC, carboxy methyl cellulose; DOX, doxorubicin; ORT, object recognition task; po, per os; RUT, rutin; SEM, standard error of the mean; veh, vehicle. 


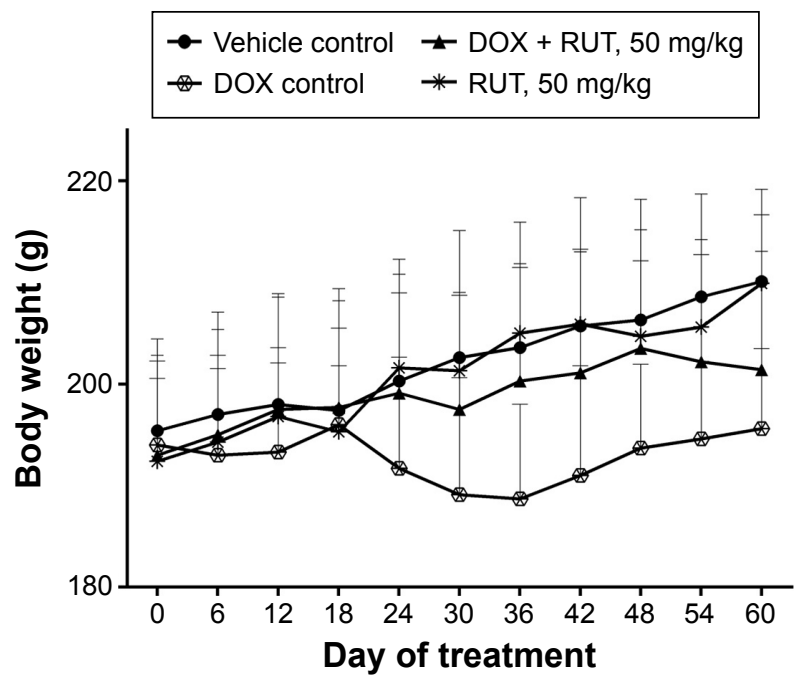

Figure 9 Effect of treatments on body weight of animals.

Notes: Illustration represents time course of change in body weight and the effect of RUT on DOX-induced body weight change $(n=9)$.

Abbreviations: DOX, doxorubicin; RUT, rutin.

compared to vehicle control samples. Treatment with DOX along with RUT at $50 \mathrm{mg} / \mathrm{kg}$, po, protected pathological changes observed with DOX control samples. This indicates that RUT is able to reverse the pathological abnormalities induced by DOX to the major organ systems and preserves their structural integrity and function (Figure 12).

\section{Discussion}

Oncologists often receive complaints from breast cancer survivors following the standard-/high-dose chemotherapy on cognitive complications for diverse components of memory, viz, episodic, working memories, difficulty in multitasking, attention, planning, etc. Increasing evidence shows that chemotherapeutic agents, because of their nonspecific effects, are highly toxic to the rapidly proliferating neuronal cells like adult hippocampal neuronal stem cells. These agents also cause excessive activation of microglial cells that can ultimately lead to neuroinflammation and death.

The first report on chemotherapy-related cognitive dysfunction was made in the 1980 s, which revealed that patients undergoing chemotherapy for various cancers like leukemia, Hodgkin's disease, digestive and respiratory malignancies, etc, performed significantly low on various neuropsychological cognitive tests. ${ }^{47}$ This study also identified the fact that permeation of chemotherapeutic agents into the brain was not a prerequisite for inducing chemofog condition that resulted from a noncentral nervous system-directed chemotherapy. Although most of the cytotoxic agents do not cross blood-brain barrier effectively (eg, DOX), they still produce chemobrain-associated cognitive dysfunction through their peripheral cytotoxic effects in animals. ${ }^{48}$

Increased levels of oxidative free radicals like ROS, RNS, and peroxynitrite $\left(\mathrm{ONOO}^{-}\right)$in the periphery that can easily cross blood-brain barrier are deleterious to normal cell population as a result of protein and lipid oxidation products such as protein carbonyls, 3-nitrotyrosine and malondialdehyde, 4-hydroxy nonenal, etc. ${ }^{49}$ Furthermore, in rodent studies, DOX was found to increase the susceptibility of brain mitochondria to calcium-induced permeability transition pore opening and oxidative stress predisposing neuronal cells to degeneration. ${ }^{50}$ Hence, we have selected to study DOX-induced chemobrain and to test RUT as a possible intervention.

To date, no novel chemical entities are found to be effective to alleviate the symptoms of chemofog. There is a great need for animal studies to explore cognitive impairment objectively following the cytostatic treatment and also to identify possible underlying mechanism. Hence, in this study, we demonstrated neuroprotective potential of a flavonoid glycoside, ie, RUT against DOX toxicity in neuronal cells.
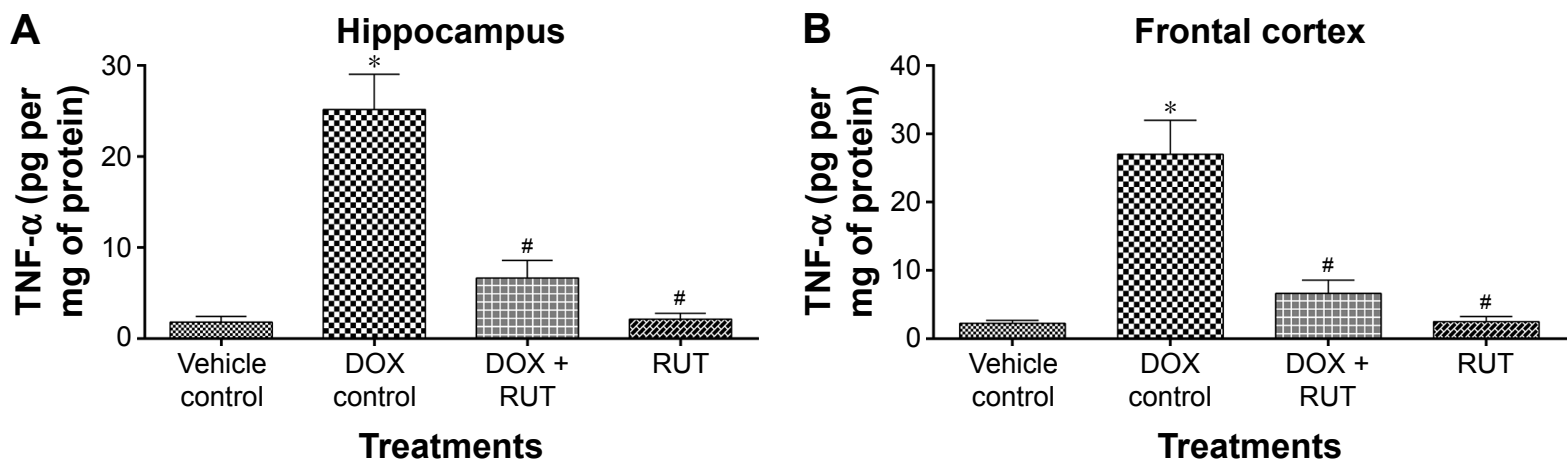

Figure 10 Effect of treatments on TNF- $\alpha$ levels in brain regions.

Notes: Illustration represents mean \pm SEM of TNF- $\alpha$ level in $(\mathbf{A})$ hippocampus and $(\mathbf{B})$ frontal cortex regions, $* P<0.00$ I compared to vehicle control, ${ }^{*}<<0.00$ I compared to DOX control $(n=6)$. RUT significantly prevented the elevated levels of TNF- $\alpha$ in both hippocampus and frontal cortex regions in brain.

Abbreviations: TNF- $\alpha$, tumor necrosis factor alpha; DOX, doxorubicin; SEM, standard error of the mean; RUT, rutin. 
A

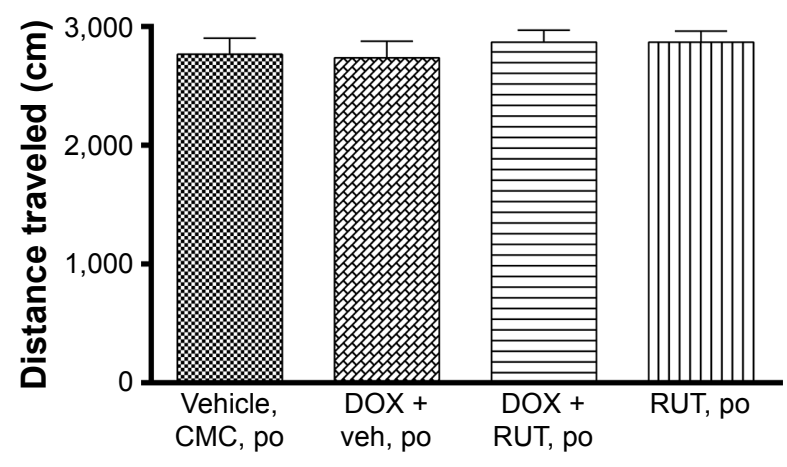

Treatments
B

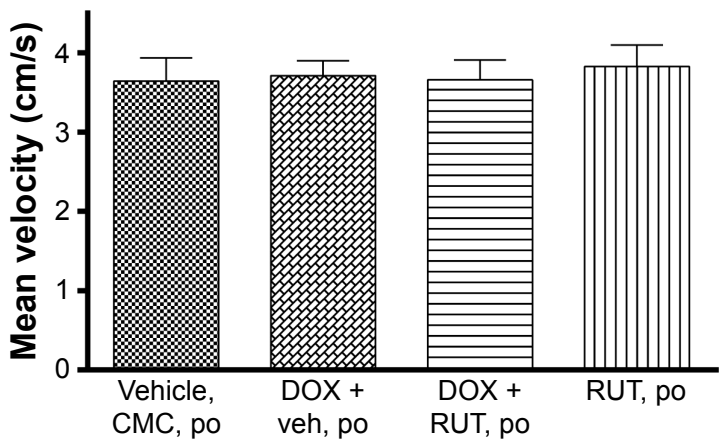

Treatments

Figure I I Effect of treatments on locomotion in OF test.

Notes: Illustration represents locomotor activity for the effect of RUT and DOX on (A) mean distance traveled and (B) mean velocity using an OF task ( $\mathrm{n}=6$ ).

Abbreviations: CMC, carboxy methyl cellulose; DOX, doxorubicin; OF, open field; po, per os; RUT, rutin; veh, vehicle.

This was followed by in vivo evaluation of RUT in an established model of chronic DOX-induced chemobrain condition accompanying memory deficits in female Wistar rats.

In clinical oncology, the chemotherapy regimen often comprises a combination of different cytotoxic agents to treat various cancers. However, it is equally essential to assess the individual chemotherapeutic agents for their potential contribution to induce a chemobrain-like condition. DOX is the most widely used cytotoxic drug for many forms of cancer. Further, it is a known fact that despite its use globally for many forms of cancers, not much attention has been paid to DOX-induced neurotoxicity and its role in inducing cognitive impairment. Hence, we focused mainly on DOXinduced neurotoxicity and also the associated cognitive impairment in vivo.

We hypothesize that natural flavonoid, RUT, through its pleiotropic actions, may combat chemotherapy-related cognitive dysfunction. Furthermore, we tried to identify the mechanism underlying the protective potential of RUT against DOX-induced chemobrain through in vitro neuroprotection studies in IMR32 neuronal cells. IMR32, the human neuroblastoma cell line, is widely used in vitro system to assess the neuroprotective ability (with regard to neuronal damage, morphological changes, and neuritogenic effects) of novel test compounds. ${ }^{51-54}$

In vitro studies revealed that DOX produced neuronal death in IMR32 cells, while prior treatment with RUT resulted in significant protection against DOX-induced neurotoxicity in a dose-dependent manner, as described in MTT assay. Furthermore, it was evident that the neuroprotective effect of RUT was through reducing the generation of intracellular ROS and apoptotic bodies induced by DOX treatment.

With the aforementioned promising neuroprotective effects, the flavonoid, RUT was further evaluated in vivo for its potential to ameliorate chemobrain (DOX)-associated episodic like memory deficits. We assessed RUT in vivo for its chemobrain preventing potential in a well-established DOX-induced chemofog animal model, which is associated with episodic memory deficits. ${ }^{35}$

Memory of autobiographical events in relation to times and places is termed as episodic memory and is most useful form of memory to accomplish the day-to-day activities in

Table 3 Hematological profiling

\begin{tabular}{|c|c|c|c|c|}
\hline \multirow[t]{2}{*}{ Parameters } & \multicolumn{4}{|l|}{ Treatment group } \\
\hline & Vehicle control & DOX control & RUT + DOX & RUT \\
\hline $\mathrm{RBC}\left(\times 10^{6}\right.$ cells $\left./ \mu \mathrm{L}\right)$ & $8.04 \pm 0.146$ & $5.89 \pm 0.219 *$ & $9.07 \pm 0.42^{\#}$ & $9.28 \pm 0.124^{\#}$ \\
\hline $\mathrm{Hb} \%(\mathrm{~g} / \mathrm{dL})$ & $12.96 \pm 0.172$ & $9.81 \pm 0.158^{*}$ & $13.82 \pm 0.385^{\#}$ & $14.14 \pm 0.283^{\#}$ \\
\hline WBC $\left(\times 10^{3}\right.$ cells $\left./ \mu \mathrm{L}\right)$ & $8.66 \pm 0.682$ & $7.21 \pm 0.48$ & $7.32 \pm 0.676$ & $8.17 \pm 0.516$ \\
\hline Granulocytes $\left(\times 10^{3}\right.$ cells $\left./ \mu \mathrm{L}\right)$ & $1.28 \pm 0.098$ & $1.04 \pm 0.073$ & $1.22 \pm 0.145$ & $1.3 \pm 0.278$ \\
\hline Lymphocytes $\left(\times 10^{3}\right.$ cells $\left./ \mu \mathrm{L}\right)$ & $7.04 \pm 0.549$ & $6.62 \pm 0.458$ & $7.33 \pm 0.267$ & $7.85 \pm 0.289$ \\
\hline Monocytes $\left(\times 10^{3}\right.$ cells $\left./ \mu \mathrm{L}\right)$ & $1.11 \pm 0.103$ & $1.05 \pm 0.05$ & $1.11 \pm 0.115$ & $0.88 \pm 0.068$ \\
\hline Platelets $\left(\times 10^{3}\right.$ cells $\left./ \mu \mathrm{L}\right)$ & $548.1 \mathrm{I} \pm 23.545$ & $521.11 \pm 22.497$ & $523.88 \pm 31.023$ & $581.55 \pm 17.84$ \\
\hline
\end{tabular}

Notes: Data represent mean \pm SEM of various hematological parameters, $* P<0.01$ compared to vehicle control, ${ }^{*} P<0.01$ compared to $D O X$ control ( $n=6$ ). Abbreviations: DOX, doxorubicin; RUT, rutin; RBC, red blood cells; Hb, hemoglobin; WBC, white blood cells; SEM, standard error of the mean. 
Table 4 Effect of treatments on oxidative stress markers in brain

\begin{tabular}{|c|c|c|c|c|c|c|c|c|}
\hline \multirow[t]{2}{*}{ Treatment } & \multicolumn{4}{|c|}{ Hippocampal markers } & \multicolumn{4}{|c|}{ Frontal cortex markers } \\
\hline & $\begin{array}{l}\text { Catalase } \\
\text { (units/mg } \\
\text { of protein) }\end{array}$ & $\begin{array}{l}\text { SOD } \\
\text { (units/mg of } \\
\text { protein) }\end{array}$ & $\begin{array}{l}\text { GSH } \\
\text { ( } \mu \text { g/mg of } \\
\text { protein) }\end{array}$ & $\begin{array}{l}\text { Total thiols } \\
\text { ( } \mu \mathrm{g} / \mathrm{mg} \text { of } \\
\text { protein) }\end{array}$ & $\begin{array}{l}\text { Catalase } \\
\text { (units } / \mathrm{mg} \\
\text { of protein) }\end{array}$ & $\begin{array}{l}\text { SOD } \\
\text { (units/mg of } \\
\text { protein) }\end{array}$ & $\begin{array}{l}\text { GSH } \\
(\mu \mathrm{g} / \mathrm{mg} \text { of } \\
\text { protein })\end{array}$ & $\begin{array}{l}\text { Total thiols } \\
\text { ( } \mu \mathrm{g} / \mathrm{mg} \text { of } \\
\text { protein) }\end{array}$ \\
\hline Vehicle control & $1.90 \pm 0.11$ & $12.45 \pm 1.04$ & $4.77 \pm 0.71$ & $\mathrm{II} .0 \mathrm{I} \pm 0.87$ & $2.04 \pm 0.11$ & $12.94 \pm 1.44$ & $6.68 \pm 0.66$ & $|2.98 \pm 1.0|$ \\
\hline DOX control & $0.94 \pm 0.13 *$ & $7.35 \pm 0.54^{*}$ & $2.1 I \pm 0.3 I *$ & $5.60 \pm 0.71 *$ & $1.21 \pm 0.12^{*}$ & $5.44 \pm 0.83 *$ & $3.40 \pm 0.33 *$ & $6.45 \pm 0.89 *$ \\
\hline RUT + DOX & $1.89 \pm 0.32^{\#}$ & $12.18 \pm 1.04^{\#}$ & $4.52 \pm 0.52^{\#}$ & $11.02 \pm 1.22^{\#}$ & $1.92 \pm 0.12^{\#}$ & $12.08 \pm 1.13^{\#}$ & $5.95 \pm 0.69^{\#}$ & $12.05 \pm 1.46^{\#}$ \\
\hline RUT & $2.01 \pm 0.1 I^{\#}$ & $13.08 \pm 1.12^{\#}$ & $4.90 \pm 0.42^{\#}$ & $\mid 1.31 \pm 2.08^{\#}$ & $2.19 \pm 0.13^{\#}$ & $13.56 \pm 1.10^{\#}$ & $6.55 \pm 1.12^{\#}$ & $|2.5| \pm\left. 1.3\right|^{\#}$ \\
\hline
\end{tabular}

Notes: Data represent mean \pm SEM of oxidative stress markers in hippocampal and frontal cortex regions in brain; $* P<0.01$ compared to vehicle control, $\# P<0.01$ compared to DOX control $(n=6)$.

Abbreviations: DOX, doxorubicin; RUT, rutin; SOD, superoxide dismutase; GSH, glutathione; SEM, standard error of the mean.

one's life.$^{56}$ Prefrontal cortex is mainly involved in encoding and retrieval of episodic memory. ${ }^{57,58}$ Moreover, the anatomical structures that are crucial for episodic memory include amygdala, brainstem, and hippocampus. In animal species like rodents, episodic component is generally assessed using ORT where animals encounter different episodes in which they remember different objects presented to them.

In ORT, rats treated with DOX explored both familiar and novel objects without any discrimination during choice trial, which indicates that the rats were unable to recognize either familiar or novel objects. However, the animals with saline treatment were able to discriminate the novel object from the familiar one. Treatment with RUT alone or in combination with DOX produced significant increase in recognition and discriminative indices compared to DOX control group. This showed that RUT was able to prevent the cognitive deficits associated with DOX chemotherapy. The locomotor activity was also assessed for any inhibitory or stimulatory effects influencing treatments. In our study, we did not find any significant effects on locomotion among the treatment groups that support the validity of assessing episodic memory using ORT.

Body weight recordings displayed moderate reduction in body weight for the group treated with DOX alone as

Table 5 Acetylcholinesterase activity in brain

\begin{tabular}{lll}
\hline Treatment & \multicolumn{2}{l}{$\begin{array}{l}\text { Acetylcholinesterase activity }(\mu \mathrm{M} \text { of } \\
\text { acetylthiocholine hydrolyzed/min/mg } \\
\text { of protein) }\end{array}$} \\
\cline { 2 - 3 } & Hippocampus & Frontal cortex \\
\hline Vehicle control & $8.275 \pm 0.403$ & $9.819 \pm 0.514$ \\
DOX control & $8.646 \pm 0.514$ & $9.459 \pm 0.729$ \\
RUT + DOX & $7.973 \pm 0.467$ & $9.100 \pm 0.889$ \\
RUT & $7.196 \pm 0.711$ & $8.907 \pm 0.873$ \\
\hline
\end{tabular}

Notes: Data represent mean \pm SEM of acetylcholinesterase enzyme activity in hippocampal and frontal cortex regions in brain $(n=6)$. No significant difference observed between groups.

Abbreviations: DOX, doxorubicin; RUT, rutin; SEM, standard error of the mean. compared to saline control. RUT treatment was able to reverse the DOX-induced decline in body weight and was comparable to that of vehicle group. Hematological profiling indicated that chronic DOX treatment resulted in significant reduction of $\mathrm{RBC}$ and hemoglobin levels with moderate effect on WBC and platelets compared to vehicle. However, chronic RUT treatment (alone or in combination with DOX) produced significant myeloprotective effects against DOX. Organ index difference for major organs was found to be insignificant among the treated groups.

Acetylcholinesterase activity in hippocampus and frontal cortex was almost similar across the treatment groups and no significant difference was noticed. This indicates that the pathological changes underlying chemobrain are different from those of Alzheimer's disease. In Alzheimer's disease, inhibition of acetylcholinesterase seemed to be an effective but only a symptomatic therapeutic strategy.

TNF- $\alpha$ levels have been significantly elevated in DOX control group in hippocampus and frontal cortex, which indicate an indirect neurotoxic mechanism of DOX treatment through periphery. However, this increase was significantly prevented by RUT cotreatment, which proves the potential anti-inflammatory effect of the flavonoid, RUT to alleviate chemobrain condition.

Histopathological analysis of major organs revealed chronic DOX-produced gross structural abnormalities in major organs such as liver, heart, kidney, and brain. RUT pretreatment averted these abnormalities. This shows that RUT was able to reverse the DOX-induced structural, and thereby the, functional abnormalities of major organ systems to some extent.

Growing evidence shows that adult hippocampal neurogenesis is a continuous process throughout the life span and is essential to form new recognition memories. Dentate gyrus, the hippocampal subregion, is the principal and active site of neurogenesis. Even when a small quantity of cytotoxic drugs 
Table 6 Effect of treatments on biochemical parameters

\begin{tabular}{|c|c|c|c|c|}
\hline Parameters & Vehicle control & DOX control & RUT + DOX & RUT \\
\hline AST (U/L) & $128.72 \pm 8.44$ & $122.53 \pm 4.85$ & $116.50 \pm 8.26$ & $117.68 \pm 8.15$ \\
\hline ALT (U/L) & $43.60 \pm 3.03$ & $45.47 \pm 3.19$ & $44.75 \pm 3.53$ & $43.98 \pm 2.38$ \\
\hline $\operatorname{ALP}(\mathrm{U} / \mathrm{L})$ & $103.53 \pm 5.80$ & $107.98 \pm 7.55$ & $95.44 \pm 6.16$ & $98.13 \pm 8.29$ \\
\hline CK (U/L) & $376.05 \pm 38.37$ & $801.83 \pm|67.9|^{*}$ & $398.73 \pm 52.92^{\#}$ & $421.18 \pm 37.80^{\#}$ \\
\hline Glucose (mg/dL) & $73.46 \pm 6.92$ & $81.65 \pm 2.92$ & $73.67 \pm 5.22$ & $80.28 \pm 4.20$ \\
\hline Urea (mg/dL) & $36.66 \pm 5.06$ & $96.96 \pm 8.87 * * *$ & $41.21 \pm 7.82^{\# \#}$ & $33.10 \pm 4.32^{\ldots \#}$ \\
\hline Total cholesterol (mg/dL) & $55.12 \pm 3.18$ & $86.40 \pm 3.77^{* * * *}$ & $61.54 \pm 2.17^{\# \#}$ & $58.44 \pm 3.29 \ldots \ldots$ \\
\hline Triglyceride (mg/dL) & $61.98 \pm 4.67$ & $147.58 \pm 7.53 * * *$ & $79.13 \pm 5.46^{\# \#}$ & $49.733 \pm 4.4 I^{\prime \prime m ~}$ \\
\hline Total bilirubin $(\mathrm{mg} / \mathrm{dL})$ & $0.10 \pm 0.00$ & $0.10 \pm 0.00$ & $0.08 \pm 0.02$ & $0.1 \pm 0.02$ \\
\hline Creatinine $(\mu \mathrm{mol} / \mathrm{L})$ & $31.39 \pm 2.17$ & $31.22 \pm 1.88$ & $30.06 \pm 0.55$ & $30.53 \pm 2.01$ \\
\hline Total protein (g/dL) & $7.02 \pm 0.4 I$ & $7.87 \pm 0.17$ & $6.55 \pm 0.26$ & $6.43 \pm 0.24$ \\
\hline Albumin (mg/dL) & $4.33 \pm 0.30$ & $4.52 \pm 0.23$ & $3.98 \pm 0.37$ & $4.01 \pm 0.15$ \\
\hline
\end{tabular}

Notes: Data represent mean \pm SEM of various biochemical parameters $(n=6)$. $* P<0.05,{ }^{* * *} P<0.001$ compared to vehicle control; ${ }^{\#} P<0.05$, ${ }^{\# *} P<0.01$, ${ }^{\# \#} P<0.00 \mathrm{I}$ compared to DOX control.

Abbreviations: AST, aspartate transaminase; ALT, alanine transaminase; ALP, alkaline phosphatase; CK, creatinine kinase; DOX, doxorubicin; RUT, rutin; SEM, standard error of the mean.

enters brain, it can be highly toxic to this adult hippocampal neurogenesis pool of neuronal stem cells, which can result in cognitive complications and chemofog.

Although RUT showed protective effects in this study in structural and functional assessments, not knowing the exact mechanism by which this happened is a limitation of this study. Most probable mechanisms include neuroprotection, combating the oxidative stress, blood-forming effect, and prevention of neuroinflammation (TNF- $\alpha$ ). Further studies are warranted to assess the effect of RUT in models
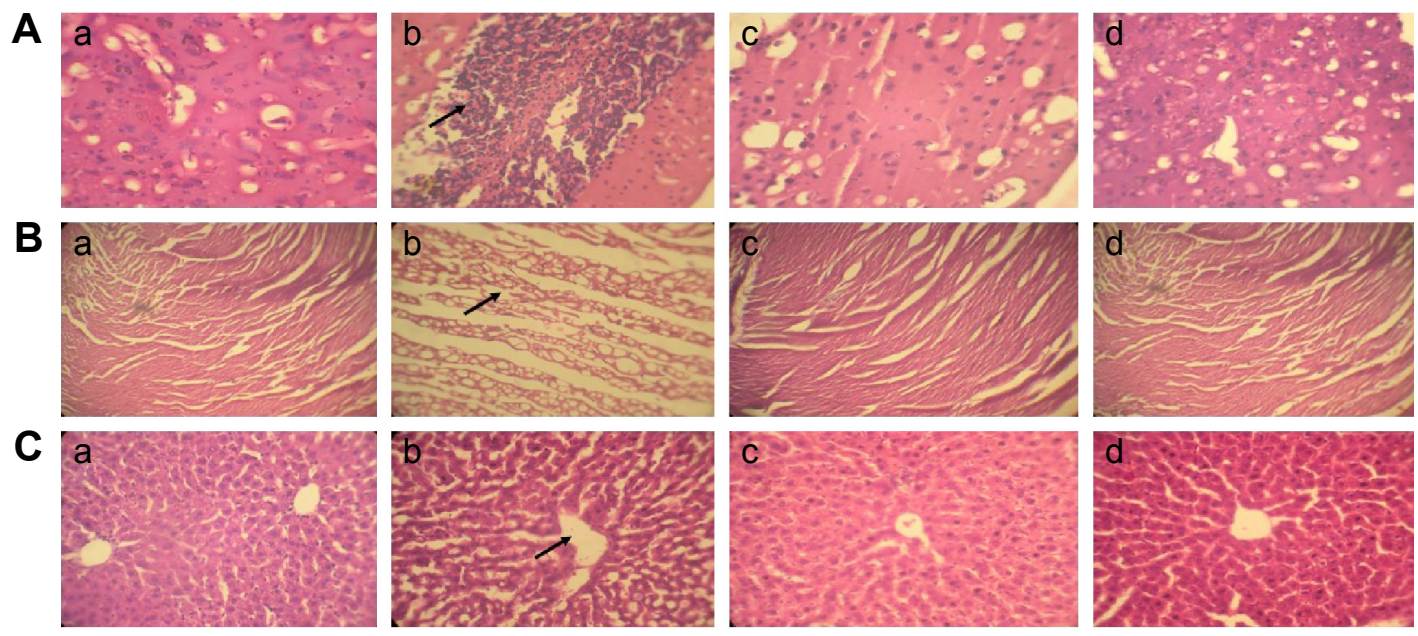

D
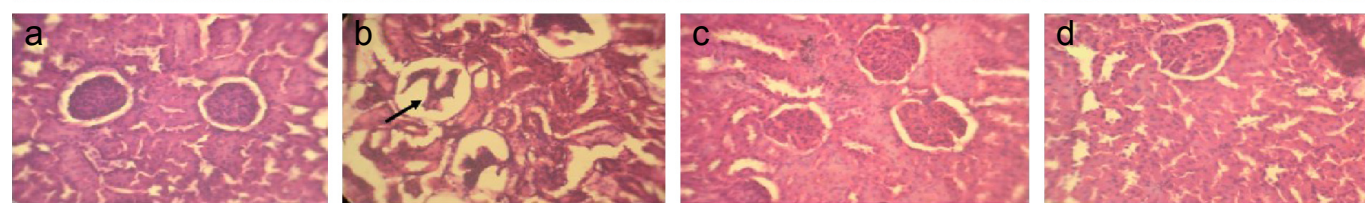

Figure 12 Histopathological analysis of major organ systems.

Notes: (A) Cerebral cortex: (a) healthy vehicle control showing normal histological signs; (b) DOX control showing irregular and degenerated morphological features along with marked gliosis; (c) rats treated with DOX and RUT $(50 \mathrm{mg} / \mathrm{kg}$, po) reflecting the minor morphological changes with reduced gliosis as compared to DOX control; (d) rats treated with only RUT showing the histological features as that of healthy control; (B) heart: (a) healthy control displaying general histological architecture of normal myocardium; (b) DOX control with numerous vacuoles and degeneration of myocardial structure; (c) rats treated with DOX and RUT (50 mg/kg, po) reflecting slight histological changes as compared to normal control; (d) rats treated with RUT only displaying healthy myocardial architecture as that of normal control; (C) liver: (a) vehicle control exhibiting histological architecture of healthy hepatocyte parenchyma and central vein with no abnormalities; (b) rats treated with DOX showing disruption of hepatocyte parenchyma with central vein dilation and necrosis; (c) RUT- and DOX-treated animals displaying minor changes of hepatocyte parenchymal and central vein histological architecture; (d) RUT- only treated group exhibiting liver histology as that of normal healthy control; (D) kidney: (a) healthy control rats showing normal histological morphology of kidney with complete renal corpuscle and proximal tubules; (b) DOX control rats showing abnormal architecture with necrosis of renal corpuscles, and proximal tubules with medullary congestion; (c) rats treated with DOX and RUT displaying healthy histological features as that of normal control; (d) RUTonly treated rats exhibiting kidney morphology as that of healthy control. Arrows in DOX control animal samples represent the histological abnormality profile to the major organ systems assessed. (All the images were captured at $40 \times$ magnification.)

Abbreviations: DOX, doxorubicin; po, per os; RUT, rutin. 
of other cognitive components and also the combination chemotherapy-induced cognitive dysfunction.

From these results, it is evident that RUT mitigates DOX-induced cognitive dysfunction, myelosuppression, and oxidative stress. This may be attributed to its antioxidant and anti-inflammatory activity. The cytotoxic action of DOX is mediated through the disruption of the redox potential in cancer cells, which leads to an environment of oxidative stress. Hence, it is imperative to verify whether RUT suppresses the side effects associated with DOX in normal cells without affecting its cytotoxic potential in cancer cells. There are reports of use of antioxidant agents as anticancer drugs. It is well established that RUT modulates Wnt, JAK-STAT, and EGF signaling, and AP-1, NF- $\mathrm{KB}$, and Akt in cancer cells, which are implicated in its anticancer property ${ }^{59} \mathrm{In}$ this regard, further studies are underway to evaluate the efficacy of RUT in the prevention of DOX-induced toxic effects in mammary carcinoma rats.

\section{Conclusion}

DOX on chronic treatment produced episodic memory deficits in Wistar rats, and the flavonoid glycoside RUT is able to prevent these deficits associated with DOX chemotherapy through its neuroprotective effect when coadministered. Hence, RUT may be a promising and potential adjuvant therapeutic intervention to alleviate the cognitive deficits associated with DOX-induced chemobrain in vivo as well as other treatment-related side effects.

\section{Acknowledgments}

The authors acknowledge Department of Pharmacology, Manipal College of Pharmaceutical Sciences, Manipal University, Manipal, Karnataka, India, for providing the laboratory facilities and infrastructure to carry out this study and also thank Manipal University's structured PhD Program (PhD Registration Number 120600101) for providing fellowship to Mr Grandhi Venkata Ramalingayya. The authors are also thankful to Dr N Gopalan Kutty, professor, Manipal College of Pharmaceutical Sciences, Manipal for linguistic editing. We thank Mr Karthik Gourishetti for his technical support in performing the flow cytometric analysis.

\section{Disclosure}

The authors report no conflicts of interest in this work.

\section{References}

1. Cherry SM, Hunt PA, Hassold TJ. Cisplatin disrupts mammalian spermatogenesis, but does not affect recombination or chromosome segregation. Mutat Res. 2004;564(2):115-128.
2. A.C.S. Cancer Facts and Figures. Atlanta, GA: American Cancer Society; 2014. Available from: http://www.cancer.org. Accessed May 5, 2016.

3. Ahles TA, Saykin AJ. Candidate mechanisms for chemotherapy-induced cognitive changes. Nat Rev Cancer. 2007;7(3):192-201.

4. Nelson CJ, Nandy N, Roth AJ. Chemotherapy and cognitive deficits: mechanisms, findings, and potential interventions. Palliat Support Care. 2007;5(3):273-280.

5. Hess LM, Insel KC. Chemotherapy-related change in cognitive function: a conceptual model. Oncol Nurs Forum. 2007;34(5):981-994.

6. Ahles TA, Saykin AJ, Furstenberg CT, et al. Neuropsychologic impact of standard-dose systemic chemotherapy in long-term survivors of breast cancer and lymphoma. J Clin Oncol. 2002;20(2):485-493.

7. Silverman DH, Dy CJ, Castellon SA, et al. Altered frontocortical, cerebellar, and basal ganglia activity in adjuvant-treated breast cancer survivors 5-10 years after chemotherapy. Breast Cancer Res Treatment. 2007;103(3):303-311.

8. Konat GW, Kraszpulski M, James I, Zhang HT, Abraham J. Cognitive dysfunction induced by chronic administration of common cancer chemotherapeutics in rats. Metab Brain Dis. 2008;23(3):325-333.

9. Ahles TA, Saykin AJ. Breast cancer chemotherapy-related cognitive dysfunction. Clin Breast Cancer. 2002;3(Suppl 3):S84-S90.

10. McDonald BC, Saykin AJ. Neurocognitive dimensions of breast cancer and its treatment. Neuropsychopharmacology. 2011;36(1):355-356.

11. Simó M, Rifà-Ros X, Rodriguez-Fornells A, Bruna J. Chemobrain: a systematic review of structural and functional neuroimaging studies. Neurosci Biobehav Rev. 2013;37(8):1311-1321.

12. Wefel JS, Lenzi R, Theriault RL, Davis RN, Meyers CA. The cognitive sequelae of standard-dose adjuvant chemotherapy in women with breast carcinoma: results of a prospective, randomized, longitudinal trial. Cancer. 2004;100(11):2292-2299.

13. Castellon SA, Ganz PA, Bower JE, Petersen L, Abraham L, Greendale GA. Neurocognitive performance in breast cancer survivors exposed to adjuvant chemotherapy and tamoxifen. J Clin Exp Neuropsychol. 2004;26(7):955-969.

14. Fardell JE, Vardy J, Johnston IN, Winocur G. Chemotherapy and cognitive impairment: treatment options. Clin Pharmacol Ther. 2011;90(3): 366-376.

15. Portela MA, Rubiales AS, Centeno C. The use of psychostimulants in cancer patients. Curr Opin Support Palliat Care. 2011;5(2):164-168.

16. Davis J, Ahlberg FM, Berk M, Ashley DM, Khasraw M. Emerging pharmacotherapy for cancer patients with cognitive dysfunction. BMC Neurol. 2013;13:153.

17. Farver D. The use of "natural products" in clinical medicine. S D J Med. 1996;49(4):129-130.

18. Williams RJ, Spencer JP, Rice-Evans C. Flavonoids: antioxidants or signalling molecules? Free Radic Biol Medicine. 2004;36(7):838-849.

19. Wang Y, Wang L, Wu J, Cai J. The in vivo synaptic plasticity mechanism of EGb 761-induced enhancement of spatial learning and memory in aged rats. Br J Pharmacol. 2006;148(2):147-153.

20. Spencer JP. The interactions of flavonoids within neuronal signalling pathways. Genes Nutr. Dec 2007;2(3):257-273.

21. Spencer JPE. The impact of flavonoids on memory: physiological and molecular considerations. Chem Soc Rev. 2009;38(4):1152-1161.

22. Chen S, Gong J, Liu F, Mohammed U. Naturally occurring polyphenolic antioxidants modulate IgE-mediated mast cell activation. Immunology. 2000;100(4):471-480.

23. Gao Z, Xu H, Huang K. Effects of rutin supplementation on antioxidant status and iron, copper, and zinc contents in mouse liver and brain. Biol Trace Elem Res. 2002;88(3):271-279.

24. Bishnoi M, Chopra K, Kulkarni SK. Protective effect of rutin, a polyphenolic flavonoid against haloperidol-induced orofacial dyskinesia and associated behavioural, biochemical and neurochemical changes. Fundam Clin Pharmacol. 2007;21(5):521-529.

25. Koda T, Kuroda Y, Imai H. Rutin supplementation in the diet has protective effects against toxicant-induced hippocampal injury by suppression of microglial activation and pro-inflammatory cytokines: protective effect of rutin against toxicant-induced hippocampal injury. Cell Mol Neurobiol. 2009;29(4):523-531. 
26. Koda T, Kuroda Y, Imai H. Protective effect of rutin against spatial memory impairment induced by trimethyltin in rats. Nutr Res. 2008; 28(9):629-634.

27. Richetti SK, Blank M, Capiotti KM, et al. Quercetin and rutin prevent scopolamine-induced memory impairment in zebrafish. Behav Brain Res. 2011;217(1):10-15.

28. Khan MM, Ahmad A, Ishrat T, et al. Rutin protects the neural damage induced by transient focal ischemia in rats. Brain Res. 2009;1292: 123-135.

29. Javed H, Khan MM, Ahmad A, et al. Rutin prevents cognitive impairments by ameliorating oxidative stress and neuroinflammation in rat model of sporadic dementia of Alzheimer type. Neuroscience. 2012;210: $340-352$.

30. Gerlier D, Thomasset N. Use of MTT colorimetric assay to measure cell activation. J Immunol Methods. Nov 20 1986;94(1-2):57-63.

31. Nampoothiri M, Reddy ND, John J, Kumar N, Kutty Nampurath G, Rao Chamallamudi M. Insulin blocks glutamate-induced neurotoxicity in differentiated SH-SY5Y neuronal cells. Behav Neurol. 2014;2014: 674164.

32. Meijering E, Jacob M, Sarria JC, Steiner P, Hirling H, Unser M. Design and validation of a tool for neurite tracing and analysis in fluorescence microscopy images. Cytometry A. 2004;58(2):167-176.

33. Ribble D, Goldstein NB, Norris DA, Shellman YG. A simple technique for quantifying apoptosis in 96-well plates. BMC Biotechnol. 2005;5:12.

34. Wang H, Joseph JA. Quantifying cellular oxidative stress by dichlorofluorescein assay using microplate reader. Free Radic Biol Med. 1999; 27(5-6):612-616.

35. Ramalingayya GV, Gourishetti K, Kishore A, Nandakumar K. Assessment of female rats for studying episodic memory and its deficit associated with doxorubicin-induced chemobrain. Clin Exp Pharmacol Physiol. 2016;43(6):644-646.

36. Ennaceur A, Delacour J. A new one-trial test for neurobiological studies of memory in rats. 1: behavioral data. Behav Brain Res. 1988;31(1): 47-59.

37. Ennaceur A, Meliani K. Effects of physostigmine and scopolamine on rats' performances in object-recognition and radial-maze tests. Psychopharmacology. 1992;109(3):321-330.

38. Antunes M, Biala G. The novel object recognition memory: neurobiology, test procedure, and its modifications. Cogn Process. 2012;13(2): 93-110.

39. Abel EL. Behavioral effects of isatin on open field activity and immobility in the forced swim test in rats. Physiol Behav. 1995;57(3):611-613.

40. Prut L, Belzung C. The open field as a paradigm to measure the effects of drugs on anxiety-like behaviors: a review. Eur J Pharmacol. 2003; 463(1-3):3-33.

41. Moron MS, Depierre JW, Mannervik B. Levels of glutathione, glutathione reductase and glutathione S-transferase activities in rat lung and liver. Biochim Biophys Acta. 1979;582(1):67-78.

42. Misra HP, Fridovich I. The role of superoxide anion in the autoxidation of epinephrine and a simple assay for superoxide dismutase. $J$ Biol Chem. 1972;247(10):3170-3175.

43. Aebi H. Catalase. Methods in Enzymatic Analysis. New York, NY: Academic Press; 1974:673-678.
44. Buege JA, Aust SD. Microsomal lipid peroxidation. Methods Enzymol. 1978;52:302-310

45. Sedlak J, Lindsay RH. Estimation of total, protein-bound, and nonprotein sulfhydryl groups in tissue with Ellman's reagent. Anal Biochem. 1968; 25(1):192-205.

46. Ellman GL, Courtney KD, Andres V Jr, Feather-Stone RM. A new and rapid colorimetric determination of acetylcholinesterase activity. Biochem Pharmacol. 1961;7:88-95.

47. Silberfarb PM, Philibert D, Levine PM. Psychosocial aspects of neoplastic disease: II. Affective and cognitive effects of chemotherapy in cancer patients. Am J Psychiatry. 1980;137(5):597-601.

48. Joshi G, Sultana R, Tangpong J, et al. Free radical mediated oxidative stress and toxic side effects in brain induced by the anti cancer drug adriamycin: insight into chemobrain. Free Radic Res. 2005;39(11): 1147-1154.

49. DeAtley SM, Aksenov MY, Aksenova MV, Carney JM, Butterfield DA. Adriamycin induces protein oxidation in erythrocyte membranes. Pharmacol Toxicol. 1998;83(2):62-68.

50. Cardoso S, Santos RX, Carvalho C, et al. Doxorubicin increases the susceptibility of brain mitochondria to $\mathrm{Ca}(2+)$-induced permeability transition and oxidative damage. Free Radic Biol Med. 2008;45(10): 1395-1402.

51. Huang Y, Zitta K, Bein B, Scholz J, Steinfath M, Albrecht M. Effect of propofol on hypoxia re-oxygenation induced neuronal cell damage in vitro. Anaesthesia. 2013;68(1):31-39.

52. Wanakhachornkrai O, Pongrakhananon V, Chunhacha P, et al. Neuritogenic effect of standardized extract of Centella asiatica ECa233 on human neuroblastoma cells. BMC Complement Altern Med. 2013; 13:204.

53. Hanstein R, Trotter J, Behl C, Clement AB. Increased connexin 43 expression as a potential mediator of the neuroprotective activity of the corticotropin-releasing hormone. Mol Endocrinol. 2009;23(9): 1479-1493.

54. Kataria H, Wadhwa R, Kaul SC, Kaur G. Water extract from the leaves of Withania somnifera protect RA differentiated C6 and IMR-32 cells against glutamate-induced excitotoxicity. PloS One. 2012;7(5): e37080.

55. Ramalingayya GV, Nampoothiri M, Nayak PG, et al. Naringin and rutin alleviates episodic memory deficits in two differentially challenged object recognition tasks. Pharmacogn Mag. 2016;12(45): $63-70$.

56. Schacter DL, Gilbert DT, Wegner DM. Semantic and episodic memory. Psychology. 2nd ed. New York, NY: Worth, Incorporated; 2011: 240-241.

57. Fletcher PC, Shallice T, Dolan RJ. The functional roles of prefrontal cortex in episodic memory. I. Encoding. Brain. 1998;121(Pt 7): 1239-1248.

58. Fletcher PC, Shallice T, Frith CD, Frackowiak RS, Dolan RJ. The functional roles of prefrontal cortex in episodic memory. II. Retrieval. Brain. 1998;121(Pt 7):1249-1256.

59. Perk AA, Shatynska-Mytsyk I, Gercek YC, et al. Rutin mediated targeting of signaling machinery in cancer cells. Cancer Cell Int. 2014; 14(1):124
Drug Design, Development and Therapy

\section{Publish your work in this journal}

Drug Design, Development and Therapy is an international, peerreviewed open-access journal that spans the spectrum of drug design and development through to clinical applications. Clinical outcomes, patient safety, and programs for the development and effective, safe, and sustained use of medicines are the features of the journal, which

\section{Dovepress}

has also been accepted for indexing on PubMed Central. The manuscript management system is completely online and includes a very quick and fair peer-review system, which is all easy to use. Visit http://www.dovepress.com/testimonials.php to read real quotes from published authors. 